\title{
Modelling the effects of oxygen evolution in the all-vanadium redox flow battery
}

\author{
H. Al-Fetlawi, A.A. Shah*, F.C. Walsh \\ Energy Technology Research Group, School of Engineering Sciences, University of Southampton, University Road, Highfield, Southampton SO17 1BJ, United Kingdom
}

\section{A R T I C L E I N F O}

\section{Article history:}

Received 17 October 2009

Received in revised form

19 December 2009

Accepted 24 December 2009

Available online 14 January 2010

\section{Keywords:}

Redox flow battery

Oxygen evolution

Bubble formation

Mathematical model

Temperature

\begin{abstract}
A B S T R A C T
The impact of oxygen evolution and bubble formation on the performance of an all-vanadium redox flow battery is investigated using a two-dimensional, non-isothermal model. The model is based on mass, charge, energy and momentum conservation, together with a kinetic model for the redox and gas-evolving reactions. The multi-phase mixture model is used to describe the transport of oxygen in the form of gas bubbles. Numerical simulations are compared to experimental data, demonstrating good agreement. Parametric studies are performed to investigate the effects of changes in the operating temperature, electrolyte flow rate and bubble diameter on the extent of oxygen evolution. Increasing the electrolyte flow rate is found to reduce the volume of the oxygen gas evolved in the positive electrode. A larger bubble diameter is demonstrated to increase the buoyancy force exerted on the bubbles, leading to a faster slip velocity and a lower gas volume fraction. Substantial changes are observed over the range of reported bubble diameters. Increasing the operating temperature was found to increase the gas volume as a result of the enhanced rate of $\mathrm{O}_{2}$ evolution. The charge efficiency of the cell drops markedly as a consequence.
\end{abstract}

(c) 2010 Published by Elsevier Ltd.

\section{Introduction}

Energy storage systems can provide a solution to the problem of balancing the generation and consumption of power. Large quantities of energy can be stored to meet immediate changes in demand, allowing effective operation of base-load units at high and essentially constant levels of power. Life cycle costs, simplicity of operation, flexibility and the state of the technology are among the factors that determine the selection of systems for storage applications. Redox flow batteries (RFB), examples of which include the all-vanadium, vanadium/bromine, zinc-cerium and soluble lead-acid cells, are particularly suited to medium and large scale applications, including load levelling and peak shaving, uninterruptible power supplies and emergency backup [1-4].

The all-vanadium redox flow battery (VRB) employs the $\mathrm{V}(\mathrm{II}) / \mathrm{V}(\mathrm{III})$ redox couple in the negative electrolyte and the $\mathrm{V}(\mathrm{IV}) / \mathrm{V}(\mathrm{V})$ redox couple in the positive electrolyte [5]. Electrolyte solutions containing the redox couples are circulated through the electrodes via reservoirs external to the electrochemical cell. To provide electrical and vanadium ion insulation, an ion-exchange membrane, often a Nafion ${ }^{\circledR}$ type, is used to separate the positive and negative electrodes as shown in Fig. 1. The power output of the system increases with the size of the cell stack and the active electrode surface area, while the energy storage capacity increases with

\footnotetext{
* Corresponding author. Tel.: +1 778288 4292; fax: +1 6042686657

E-mail address: A.Shah@soton.ac.uk (A.A. Shah).
}

the volume of the electrolyte reservoir and the reactant concentrations. The ratio of energy storage to power demand determines how long the battery can be operated without recharging. Power can flow undiminished as long as there is fresh electrolyte to circulate through the stack. The VRB can, therefore, be tailored to specific storage applications. VRBs have several advantages over some of the established storage systems such as static lead-acid batteries, namely, high energy efficiencies of up to $90 \%$ in large installations, a decreasing cost per $\mathrm{kW}$ h at higher storage capacity and ease of maintenance. The use of the same element in both half-cells also avoids problems due to cross-contamination during long-term use. When solution cross-over occurs, the vanadium half-cell solutions can be remixed and the system returned to its original state.

Optimisation, scale-up and eventual commercialisation of VRB are dependent on an improved understanding of several issues, particularly gas evolution, electrolyte stability, carbon oxidation and membrane fouling. The effects associated with gas evolution on the performance and longevity of VRBs are still largely unknown. Side reactions consume a portion of the current density applied to the cell and, therefore, lower its efficiency. Bubble formation reduces the electrolyte volume in the electrodes, lowering the active surface area for reaction and affecting the bulk transport coefficients of the reactants and the bulk permeability of the porous electrode [6-9]. It is important to understand the extent of performance degradation and the conditions under which performance is severe affected. Shah et al. [10] investigated the effects of hydrogen evolution using a two-dimensional, transient model. The multi-phase mixture model was used to describe the transport of gas bubbles 


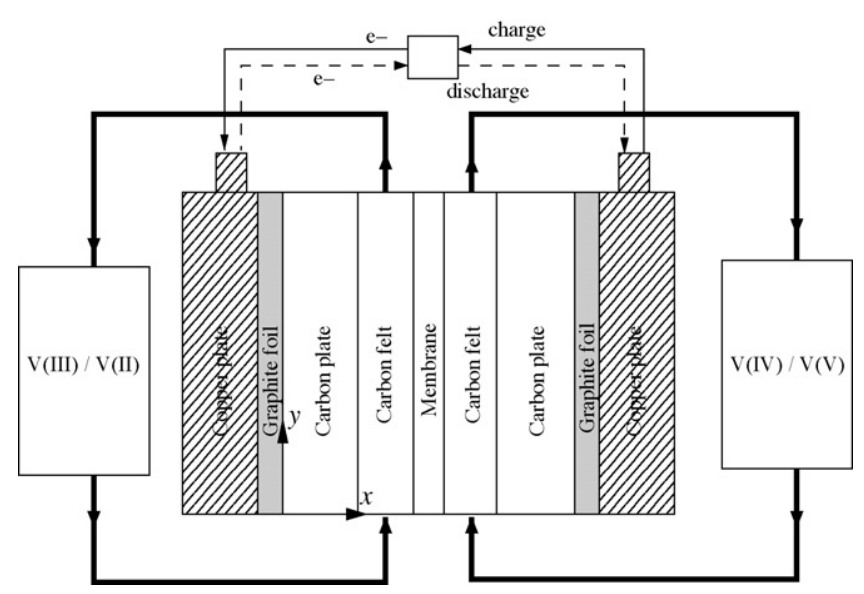

Fig. 1. A schematic of the all-vanadium battery and of the components modelled in this paper: carbon plates, porous carbon electrodes, membrane and reservoirs.

through the electrodes [11]. In this paper, $\mathrm{O}_{2}$ evolution and the accompanying gas bubble formation are studied. The framework in [10] is extended to include a thermal energy balance, previously described in [12]. The effect of $\mathrm{O}_{2}$ evolution on the efficiency of the battery and the influence of reactant concentration, temperature variations, electrolyte flow rate and bubble diameter are explored.

Details of the experimental work are given in the next section. The model is presented in Section 3, together with the underlying assumptions, numerical details and the model parameters. In Section 4, the simulation results are discussed, along with comparisons to the experimental data. The results are summarised and conclusions are drawn in Section 5.

\section{Experimental}

The cell was symmetrical about the Nafion ${ }^{\circledR} 117$ ion-exchange membrane $(150 \mathrm{~mm} \times 150 \mathrm{~mm} \times 0.1 \mathrm{~mm})$. Each half-cell consisted of a PVC outer plate $(200 \mathrm{~mm} \times 200 \mathrm{~mm} \times 20 \mathrm{~mm})$, a copper and plate $(150 \mathrm{~mm} \times 150 \mathrm{~mm} \times 3 \mathrm{~mm})$, a graphite foil $(150 \mathrm{~mm} \times 150 \mathrm{~mm} \times 2 \mathrm{~mm})$, a carbon end plate $(150 \mathrm{~mm} \times$ $150 \mathrm{~mm} \times 6.35 \mathrm{~mm})$ and a Sigratherm GFA5 carbon felt $(100 \mathrm{~mm} \times$ $100 \mathrm{~mm} \times 4 \mathrm{~mm}$ ). The cell assembly was compressed using PTFE gaskets as seals (with M6 stainless steel tie bolts). Electrical connections to the copper end plates were made using tight-screwed connections.

A peristaltic pump was used to circulate the electrolyte (as a $\mathrm{V}(\mathrm{III}) / \mathrm{V}(\mathrm{IV})$ mixture in $4000 \mathrm{~mol} \mathrm{~m}^{-3} \mathrm{H}_{2} \mathrm{SO}_{4}$ ) from a glass reservoir of volume $250 \mathrm{~mL}$, with a nitrogen gas atmosphere at a temperature of $297 \pm 2 \mathrm{~K}$. The cell was charged and discharged at a constant current of $10 \mathrm{~A}$, corresponding to a current density of $100 \mathrm{~mA} \mathrm{~cm}^{-2}$, based on the projected area of each electrode. An in-house personal computer and interface was used to monitor the cell potential difference and current. An open-circuit cell, divided by a Nafion ${ }^{\circledR} 117$ cation exchange membrane and containing a graphite rod electrode in each compartment was used to monitor the cell potential difference between carbon-rod electrodes. The ratios of oxidised to reduced species, which indicated the state of charge, were estimated using a Nernst equation applied to the monitoring cell:

$E_{\text {cell }}=E_{0,1}-E_{0,2}+\frac{2.3 R T}{F} \log _{10}\left(\frac{[\mathrm{V}(\mathrm{V})]}{[\mathrm{V}(\mathrm{IV})]} \frac{[\mathrm{V}(\mathrm{II})]}{[\mathrm{V}(\mathrm{III})]}\right)$

where $E_{1}^{0}$ and $E_{2}^{0}$ are the standard potentials for positive and negative electrode reactions (1) and (2), respectively.

\section{Model assumptions and development}

The kinetics of reduction and oxidation at the electrodes are approximated by the following simplified set of half-cell reactions, the forward direction representing charge conditions:

Positive electrode : $\mathrm{VO}^{2+}+\mathrm{H}_{2} \mathrm{O} \rightleftharpoons \mathrm{VO}_{2}^{+}+2 \mathrm{H}^{+}+\mathrm{e}^{-}$

Negative electrode $: \mathrm{V}(\mathrm{III})+\mathrm{e}^{-} \rightleftharpoons \mathrm{V}(\mathrm{II})$

The actual kinetics are highly complex [14,15] but the work of Shah and coworkers [12,13] has demonstrated that the above mechanism provides a good approximation.

In this paper, the evolution of oxygen in the positive electrode on charge, a known side reaction $[15,16]$ with the effects of operating temperature are also incorporated into the model:

$2 \mathrm{H}_{2} \mathrm{O} \rightleftharpoons \mathrm{O}_{2}+4 \mathrm{H}^{+}+4 \mathrm{e}^{-}$

The species considered are V(II), V(III), V(IV), V(V), $\mathrm{H}_{2} \mathrm{O}, \mathrm{H}^{+}$, $\mathrm{HSO}_{4}{ }^{-}, \mathrm{O}_{2}$ and $\mathrm{SO}_{4}{ }^{2-}$. The basic model equations and boundary conditions were derived in [13] for the case without gas evolution and were later extended to include a thermal energy balance [12] and hydrogen gas formation [10]. The model is only briefly described below and the reader is referred to the earlier papers for further details. The following simplifying assumptions are made:

1. The dilute-solution approximation is used [17], and the flow is considered laminar and incompressible, due to the fact that the bulk of the electrolyte is water.

2. The overall momentum equation for the gas bubbles and electrolyte is approximated by that of the liquid since the liquid volume fraction and density are much larger than those of gaseous oxygen.

3. The oxygen gas forms spherical bubbles that maintain their shape when detaching from the electrode surface and do not coalesce $[10,18-20]$. Small bubbles remain spherical as a result of high surface tension and their coalescence can be neglected [21]. This is believed to be a result of repulsive electrical forces acting between the bubbles [22].

4. The gas-phase and liquid-phase pressures are equal, which is a good approximation for non-expanding bubbles [23,24].

5. The liquid and solid phases in the electrodes attain the same temperature.

Included in the solution domain are the carbon plates, the electrodes, the membrane and the reservoirs, as depicted in Fig. 1.

In the porous carbon electrodes, the evolved oxygen bubbles in the electrolyte are dispersed, while the electrolyte forms a continuous phase. The volume fractions of gas, $\alpha_{g}$, and liquid, $\alpha_{l}$, are constrained by volume conservation: $\alpha_{l}+\alpha_{g}=1$. In the following, $\rho_{l}$ and $\rho_{g}$ are the liquid-phase and gas-phase densities and $\vec{u}_{l}=(u, v)$ and $\vec{u}_{g}=\left(u_{g}, v_{g}\right)$ are the liquid-phase and gas-phase velocities, respectively.

The liquid velocity, $\vec{u}_{l}$, is given by continuity and Darcy's law, combined with the Kozeny-Carman relationship for hydraulic conductivity [25]:

$\nabla \cdot \vec{u}_{l}=0 ; \quad \vec{u}_{l}=-\frac{d_{f}^{2}}{K \mu_{l}} \frac{\epsilon^{3}\left(1-\alpha_{g}\right)^{3}}{\left(1-\epsilon\left(1-\alpha_{g}\right)\right)^{2}} \nabla p$

where $\epsilon$ is the electrode porosity, $p$ is the liquid-phase pressure, $\mu_{l}$ is the dynamic viscosity of the liquid, $d_{f}$ is the mean pore diameter in the electrode and $K$ is the Kozeny-Carman constant for a fibrous medium. Since the liquid-phase density and volume fraction are much greater than those of the gas phase, the overall momentum equation is approximated by that of the liquid, $\nabla \cdot \vec{u}_{l}=0$. In the absence of turbulence, the electrolyte and bubble velocities are related by $\vec{u}_{\text {slip }}=\vec{u}_{g}-\vec{u}_{l}$, where $\vec{u}_{\text {slip }}=\left(u_{\text {slip }}, v_{\text {slip }}\right)$ is the so-called 
Table 1

Sources and sinks for the liquid phase in Eq. (7).

\begin{tabular}{lll}
\hline Source term & Positive electrode & Negative electrode \\
\hline $\begin{array}{l}S_{g} \text { (oxygen volume fraction } \\
\text { equation) }\end{array}$ & $M_{\mathrm{O}_{2}} \nabla \cdot \vec{j}_{\mathrm{O}_{2}} / F$ & $\mathrm{n} / \mathrm{a}$ \\
$\begin{array}{l}S_{2} \text { (V(II) concentration } \\
\text { equation) }\end{array}$ & $\mathrm{n} / \mathrm{a}$ & $\nabla \cdot \vec{j}_{2} / F$ \\
$\begin{array}{l}S_{3} \text { (V(III) concentration } \\
\text { equation) }\end{array}$ & $\mathrm{n} / \mathrm{a}$ & $-\nabla \cdot \vec{j}_{2} / F$ \\
$\begin{array}{l}S_{4}(\mathrm{~V}(\mathrm{IV}) \text { concentration } \\
\text { equation) }\end{array}$ & $-\nabla \cdot \vec{j}_{1} / F$ & $\mathrm{n} / \mathrm{a}$ \\
$\begin{array}{l}S_{5} \text { (V(V) concentration } \\
\text { equation) }\end{array}$ & $\nabla \cdot \vec{j}_{1} / F$ & $\mathrm{n} / \mathrm{a}$ \\
$\begin{array}{l}S_{\mathrm{H}_{2} \mathrm{O}} \text { (water concentration } \\
\text { equation) }\end{array}$ & $-\nabla \cdot \vec{j}_{1} / F$ & $\mathrm{n} / \mathrm{a}$ \\
$\begin{array}{l}S_{\mathrm{H}^{+}} \text {(proton concentration } \\
\text { equation) }\end{array}$ & $\mathrm{n} / \mathrm{a}$ & $2 \nabla \cdot \vec{j}_{1} / F$ \\
\hline
\end{tabular}

slip velocity. If it is further assumed that the pressure forces on the bubble are balanced by the viscous drag, a force balance on a bubble yields an expression for the slip velocity [11]:

$\vec{u}_{\text {slip }}=\frac{1}{18 \mu_{l}} d_{g}^{2} \nabla p$

where $d_{g}$ is the bubble diameter.

The volume fraction of oxygen bubbles is determined from a mass balance:

$\epsilon \rho_{g} \frac{\partial \alpha_{g}}{\partial t}+\epsilon \rho_{g} \nabla \cdot\left(\alpha_{g} \vec{u}_{g}\right)=-S_{g}$

where the rate of $\mathrm{O}_{2}$ evolution, $S_{g}$ is given in Table 1 and discussed below.

Let $c_{i}$ denote the concentration of each species $i$ considered. Mass balances in the porous electrode regions yield:

$\frac{\partial}{\partial t}\left(\epsilon\left(1-\alpha_{g}\right) c_{i}\right)+\nabla \cdot\left(\vec{u}_{l} c_{i}-D_{i}^{\mathrm{eff}} \nabla c_{i}-\frac{z_{i} c_{i}}{R T} D_{i}^{\mathrm{eff}} \nabla \phi_{e}\right)=-S_{i}$

where the source terms, $S_{i}$, representing consumption by electrochemical reaction, are defined in Table 1 . The Nernst-Planck equation has been used for the concentration flux [17], in which $\phi_{e}$ is the electrolyte potential, $z_{i}$ is the charge of species $i$ and $D_{i}^{\text {eff }}=$ $D_{i} \epsilon^{3 / 2}\left(1-\alpha_{g}\right)^{3 / 2}$ is the effective diffusion coefficient of species $i$, i.e., the free-space value, $D_{i}$ subject to a Bruggemann correction [26]. Transport parameter values are given in Table 2 .

Charge conservation demands that the charge entering the electrolyte, $\vec{j}_{e}$, is balanced by the charge leaving the solid phase, $\vec{j}_{s}$. The total current density transferred from the solid phase to the electrolyte, $\nabla \cdot \vec{j}=\nabla \cdot \vec{j}_{e}=-\nabla \cdot \vec{j}_{s}$, is equal to the net volumetric rate of electrochemical reaction (derived below) multiplied by Faraday's constant and the number of electrons transferred. Since the electrolyte is electroneutral, $\sum_{i} z_{i} c_{i}=0$, the total current density in the electrolyte satisfies [13]:

$-\nabla \cdot\left(\sigma_{e}^{\mathrm{eff}} \nabla \phi_{e}+F \sum_{i} z_{i} D_{i}^{\mathrm{eff}} \nabla c_{i}\right)=\nabla \cdot \vec{j}$

where $\sigma_{e}^{\text {eff }}=\left(F^{2} / R T\right) \sum_{i} z_{i}^{2} D_{i}^{\text {eff }} c_{i}$ is the effective electrolyte conductivity. $T$ is the cell temperature and $R$ is the molar gas constant. This equation is applied only in the porous carbon electrodes.
Table 2

Default values for constants related to the transport of charge and mass.

\begin{tabular}{|c|c|c|}
\hline Symbol & Quantity & Size \\
\hline$D_{2}$ & V(II) diffusion coefficient in electrolyte & $2.4 \times 10^{-10} \mathrm{~m}^{2} \mathrm{~s}^{-1}[40]$ \\
\hline$D_{3}$ & V(III) diffusion coefficient in electrolyte & $2.4 \times 10^{-10} \mathrm{~m}^{2} \mathrm{~s}^{-1}[40]$ \\
\hline$D_{4}$ & V(IV) diffusion coefficient in electrolyte & $3.9 \times 10^{-10} \mathrm{~m}^{2} \mathrm{~s}^{-1}[40]$ \\
\hline$D_{5}$ & $\mathrm{~V}(\mathrm{~V})$ diffusion coefficient in electrolyte & $3.9 \times 10^{-10} \mathrm{~m}^{2} \mathrm{~s}^{-1}[40]$ \\
\hline$D_{\mathrm{H}_{2} \mathrm{O}}$ & $\begin{array}{l}\text { Water diffusion coefficient in } \\
\text { electrolyte }\end{array}$ & $2.3 \times 10^{-9} \mathrm{~m}^{2} \mathrm{~s}^{-1}[41]$ \\
\hline$D_{w}$ & $\begin{array}{l}\text { Water diffusion coefficient in the } \\
\text { membrane }\end{array}$ & $5.75 \times 10^{-10} \mathrm{~m}^{2} \mathrm{~s}^{-1}[42]$ \\
\hline$D_{\mathrm{H}^{+}}$ & $\begin{array}{l}\text { Proton diffusion coefficient in the } \\
\text { membrane }\end{array}$ & $1.4 \times 10^{-9} \mathrm{~m}^{2} \mathrm{~s}^{-1}[43]$ \\
\hline$D_{\mathrm{HSO}_{4}^{-}}$ & $\begin{array}{l}\mathrm{HSO}_{4}{ }^{-} \text {diffusion coefficient in the } \\
\text { membrane }\end{array}$ & $1.4 \times 10^{-9} \mathrm{~m}^{2} \mathrm{~s}^{-1}[43]$ \\
\hline$D_{\mathrm{SO}_{4}^{2-}}$ & $\begin{array}{l}\mathrm{SO}_{4}{ }^{2-} \text { diffusion coefficient in the } \\
\text { membrane }\end{array}$ & $1.4 \times 10^{-9} \mathrm{~m}^{2} \mathrm{~s}^{-1}[43]$ \\
\hline$K$ & $\begin{array}{l}\text { Kozeny-Carman constant: porous } \\
\text { electrode }\end{array}$ & $5.55[44]$ \\
\hline$\kappa_{\phi}$ & $\begin{array}{l}\text { Electrokinetic permeability: } \\
\text { membrane }\end{array}$ & $1.13 \times 10^{-19} \mathrm{~m}^{2}[43]$ \\
\hline$\kappa_{p}$ & Hydraulic permeability: membrane & $1.58 \times 10^{-18} \mathrm{~m}^{2}[45]$ \\
\hline$\mu_{\mathrm{H}_{2} \mathrm{O}}$ & Water viscosity & $10^{-3} \mathrm{Pas}$ \\
\hline$\sigma_{f}$ & $\begin{array}{l}\text { Electronic conductivity of porous } \\
\text { carbon electrode }\end{array}$ & $363 \mathrm{~S} \mathrm{~m}^{-1 a}$ \\
\hline$\sigma_{c}$ & $\begin{array}{l}\text { Electronic conductivity of carbon } \\
\text { plates }\end{array}$ & $5000 \mathrm{Sm}^{-1 \mathrm{a}}$ \\
\hline
\end{tabular}

a Manufacturer's estimate.

The electronic potential is given by [13]:

$-\sigma_{s} \nabla^{2} \phi_{s}= \begin{cases}-\nabla \cdot \vec{j} & \text { carbon electrodes } \\ 0 & \text { carbon plates }\end{cases}$

In the carbon electrodes, the electronic conductivity is $\sigma_{s}=$ $(1-\epsilon)^{3 / 2} \sigma_{f}$, where $\sigma_{f}$ is the electronic conductivity of carbon, and in the carbon plates, $\sigma_{s}=\sigma_{c}$.

The dissolved water concentration in the membrane, $c_{\mathrm{H}_{2} \mathrm{O}}$ is given by [13]:

$\frac{\partial c_{\mathrm{H}_{2} \mathrm{O}}}{\partial t}-\nabla \cdot\left(D_{w} \nabla c_{\mathrm{H}_{2} \mathrm{O}}\right)+\nabla \cdot\left(\vec{u}_{l} c_{\mathrm{H}_{2} \mathrm{O}}\right)=0$

where $D_{w}=4.17 \times 10^{-8} \lambda\left(1+161 e^{-\lambda}\right) \exp (-2436 / T)$ is the dissolved water diffusion coefficient [27] and $\lambda=22$ is the water content of a liquid-saturated membrane. The liquid velocity, $\vec{u}_{l}$, is subject to an incompressibility constraint, $\nabla \cdot \vec{u}_{l}=0$, and is given by Schloegl's equation:

$\vec{u}_{l}=-\frac{\kappa_{\phi}}{\mu_{\mathrm{H}_{2} \mathrm{O}}} F c_{\mathrm{H}^{+}} \nabla \phi_{e}-\frac{\kappa_{p}}{\mu_{\mathrm{H}_{2} \mathrm{O}}} \nabla p$

where $\kappa_{\phi}$ is the electrokinetic permeability and $\kappa_{p}$ is the hydraulic permeability. Electroneutrality in the membrane demands a fixed proton concentration, $c_{\mathrm{H}^{+}}=-z_{f} c_{f}$, where $c_{f}$ is the fixed-charge site concentration in the membrane and $z_{f}$ is the fixed-site charge [13] The equation for current conservation in the membrane can be derived using Eq. (11) and the incompressibility condition:

$-\frac{F^{2}}{R T} D_{\mathrm{H}^{+}} c_{\mathrm{H}^{+}} \nabla^{2} \phi_{e}=0$

An energy balance for the entire region (carbon plates, porous electrodes and membrane) was derived in [12], taking into account heat conduction, convective heat transport, the heats of reaction and

Table 3

Sources and sinks for the energy Eq. (13). They are, from top to bottom, heating by activation losses, electrochemical reaction and ohmic resistance.

\begin{tabular}{|c|c|c|c|c|}
\hline Term & Membrane & - ve electrode & + ve electrode & Current collector \\
\hline$q_{\text {act }}$ & 0 & $\eta_{1} \nabla \cdot \vec{j}_{1}$ & $\eta_{2} \nabla \cdot \vec{j}_{2}$ & 0 \\
\hline$q_{\mathrm{rev}}$ & 0 & $-\Delta S_{1} T \nabla \cdot \vec{j}_{1} / F$ & $\Delta S_{2} T \nabla \cdot \vec{j}_{2} / F$ & 0 \\
\hline$q_{\mathrm{ohm}}$ & $\sigma_{m}^{\text {eff }}|\nabla \phi|^{2}$ & $\sigma_{s}^{\text {eff }}|\nabla \psi|^{2}+\sigma_{e}^{\text {eff }}|\nabla \phi|^{2}$ & $\sigma_{s}^{\text {eff }}|\nabla \psi|^{2}+\sigma_{e}^{\text {eff }}|\nabla \phi|^{2}$ & $\sigma_{c}|\nabla \psi|^{2}$ \\
\hline
\end{tabular}


Table 4

Default parameter values for the heat Eq. (13).

\begin{tabular}{|c|c|c|}
\hline Symbol & Quantity & Size \\
\hline$\lambda_{l}$ & $\begin{array}{l}\text { Electrolyte thermal } \\
\text { conductivity }\end{array}$ & $0.67 \mathrm{~W} \mathrm{~m}^{-1} \mathrm{~K}^{-1}$ \\
\hline$\lambda_{e}$ & Electrode thermal conductivity & $0.15 \mathrm{~W} \mathrm{~m}^{-1} \mathrm{~K}^{-1}$ \\
\hline$\lambda_{m}$ & $\begin{array}{l}\text { Membrane thermal } \\
\text { conductivity [38] }\end{array}$ & $0.67 \mathrm{~W} \mathrm{~m}^{-1} \mathrm{~K}^{-1}$ \\
\hline$\lambda_{c}$ & $\begin{array}{l}\text { Current collector thermal } \\
\text { conductivity }\end{array}$ & $16 \mathrm{~W} \mathrm{~m}^{-1} \mathrm{~K}^{-1}$ \\
\hline$\lambda_{\text {air }}$ & $\begin{array}{l}\text { Thermal conductivity of air at } \\
293 \mathrm{~K}\end{array}$ & $0.0257 \mathrm{~W} \mathrm{~m}^{-1} \mathrm{~K}^{-1}$ \\
\hline$\rho_{l} C_{l}$ & $\begin{array}{l}\text { Liquid thermal capacitance } \\
\text { (water) }\end{array}$ & $4.187 \times 10^{6} \mathrm{~J} \mathrm{~m}^{-3} \mathrm{~K}^{-1}$ \\
\hline$\rho_{e} C_{e}$ & $\begin{array}{l}\text { Porous electrode thermal } \\
\text { capacitance }^{\text {a }}\end{array}$ & $3.33 \times 10^{5} \mathrm{Jm}^{-3} \mathrm{~K}^{-1}$ \\
\hline$\rho_{m} C_{m}$ & $\begin{array}{l}\text { Membrane thermal } \\
\text { capacitance }^{\text {b }}\end{array}$ & $2.18 \times 10^{6} \mathrm{~J} \mathrm{~m}^{-3} \mathrm{~K}^{-1}$ \\
\hline$\rho_{c} C_{c}$ & $\begin{array}{l}\text { Current collector thermal } \\
\text { capacitance }\end{array}$ & $4.03 \times 10^{6} \mathrm{~J} \mathrm{~m}^{-3} \mathrm{~K}^{-1}$ \\
\hline$-\Delta S_{0,1}$ & $\begin{array}{l}\text { Entropy associated with } \\
\text { reaction (1) [39] }\end{array}$ & $-21.7 \mathrm{~J} \mathrm{~mol}^{-1} \mathrm{~K}^{-1}$ \\
\hline$-\Delta S_{0,2}$ & $\begin{array}{l}\text { Entropy associated with } \\
\text { reaction (2) [39] }\end{array}$ & $-100 \mathrm{~J} \mathrm{~mol}^{-1} \mathrm{~K}^{-1}$ \\
\hline$-\Delta S_{0, O_{2}}$ & $\begin{array}{l}\text { Entropy associated with } \\
\text { reaction (3) [39] }\end{array}$ & $65.35 \mathrm{~J} \mathrm{~mol}^{-1} \mathrm{~K}^{-1}$ \\
\hline
\end{tabular}

a Estimate based on a specific heat capacity for graphite of $710 \mathrm{~J} \mathrm{~kg} \mathrm{~K}^{-1}$ and a Sigratherm ${ }^{\circledR}$ GFA5 density of $469 \mathrm{~kg} \mathrm{~m}^{-3}$ (68\% porous).

b Estimate based on a specific heat capacity for water and a typical dry density of Nafion ${ }^{\circledR}, 1500 \mathrm{~kg} \mathrm{~m}^{-3}$.

ohmic heating:

$\frac{\partial}{\partial t}\left(\overline{\rho C_{p}} T\right)+\nabla \cdot\left(\vec{v} \rho_{l} C_{l} T\right)-\bar{\lambda} \nabla^{2} T=\sum_{k} q_{k}$

where $q_{k}$ (defined in Table 3). In this equation, $\rho_{l}$ and $C_{l}$ are the density and specific heat capacity of the liquid, respectively. $\bar{\lambda}$ is the volume-averaged thermal conductivity and $\overline{\rho C_{p}}$ is the volumeaveraged thermal capacitance, which are given by:

$$
\begin{array}{llrl}
\bar{\lambda}=\epsilon \alpha_{l} \lambda_{l}+\epsilon \alpha_{g} \lambda_{g}+(1-\epsilon) \lambda_{e} ; & \overline{\rho C_{p}}= & \epsilon \alpha_{l} \rho_{l} C_{l}+\epsilon \alpha_{g} \rho_{g} C_{g} \\
& & & (1-\epsilon) \rho_{e} C_{e} \\
\bar{\lambda}=\lambda_{m} ; & \overline{\rho C_{p}} & =\rho_{m} C_{m} \\
\bar{\lambda}=\lambda_{c} ; & \overline{\rho C_{p}} & =\rho_{c} C_{c}
\end{array}
$$

in the porous electrode, membrane and carbon plates, respectively. $C_{j}$ and $\lambda_{j}$ are the specific heat capacities (at constant pressure) and thermal conductivities of the individual phases: the subscripts ' $g$ ', ' $l$ ', ' $e$ ', ' $m$ ' and ' $c$ ' refer to the gas phase, liquid electrolyte, electrode, membrane and current collector, respectively.

The standard reaction entropies are given by:

$\Delta S_{0, j}=\left(\sum_{\text {products }} S_{0, j}^{\text {products }}\right)-\left(\sum_{\text {reactants }} S_{0, j}^{\text {reactants }}\right)$

where $S_{0, j}^{\text {products }}\left(S_{0, j}^{\text {reactants }}\right)$ are the standard entropies of formation of the products (reactants) in reactions (1) and (2), $j=1,2$ and reaction (3), $j=\mathrm{O}_{2}$. Their values at $298.15 \mathrm{~K}$ are listed in Table 4 . For each reaction $j$, the standard reaction entropy is related to the standard Gibbs free energy change of the reaction, $\Delta G_{0, j}$, and the standard enthalpy change of reaction, $\Delta H_{0, j}$, by the thermodynamic relation $\Delta G_{0, j}=\Delta H_{0, j}+T \Delta S_{0, j}$. Since $\Delta G_{0, j}=-n F E_{0, j}$, where $E_{0, j}$ is the standard potential of reaction $j$, the temperature dependence of $\Delta S_{0, j}$ is given by:

$-n F \frac{\partial \Delta E_{0, j}}{\partial T}=\frac{\partial \Delta G_{0, j}}{\partial T}=\Delta S_{0, j}$

The standard potentials, as functions of temperature, are given in Eq. (25) below.

\subsection{Reaction kinetics}

Butler-Volmer expressions are used for the transfer current densities in the positive and negative electrode compartments, $\nabla \cdot \vec{j}_{1}$ and $\nabla \cdot \vec{j}_{2}$, respectively [10]:

$$
\begin{aligned}
& \nabla \cdot \vec{j}_{1}=a \epsilon\left(1-\alpha_{g}\right) F k_{1} \sqrt{c_{4}^{s} c_{5}^{s}}\left[\exp \left(\frac{F \eta_{1}}{2 R T}\right)-\exp \left(-\frac{F \eta_{1}}{2 R T}\right)\right] \\
& \nabla \cdot \vec{j}_{2}=a \epsilon F k_{2} \sqrt{c_{3}^{s} c_{2}^{s}}\left[\exp \left(-\frac{F \eta_{2}}{2 R T}\right)-\exp \left(\frac{F \eta_{2}}{2 R T}\right)\right]
\end{aligned}
$$

where $A$ is the specific active surface area of the porous carbon electrode, and $k_{1}$ and $k_{2}$ are the standard rate constants for reactions (1) and (2), respectively. The porosity of the positive electrode is multiplied by a factor $\left(1-\alpha_{g}\right)$ to give the volume fraction of the liquid, taking into account the presence of the bubbles. $c_{i}^{s}$ are the reactant concentrations at the liquid-solid interfaces in the porous regions. Expressions for $c_{i}^{s}$ in terms of the bulk values, $c_{i}$ were derived in [13]:

$$
\begin{aligned}
& c_{4}^{s}=\frac{c_{4}+\epsilon\left(1-\alpha_{g}\right) k_{2} e^{-F\left(\phi_{s}-\phi_{e}-E_{0,1}^{\prime}\right) /(2 R T)}\left(\left(c_{4} / \gamma_{5}\right)+\left(c_{5} / \gamma_{4}\right)\right)}{1+\epsilon\left(1-\alpha_{g}\right) k_{2}\left(\left(1 / \gamma_{5}\right) e^{-F\left(\phi_{s}-\phi_{e}-E_{0,1}^{\prime}\right) /(2 R T)}+\left(1 / \gamma_{4}\right) e^{F\left(\phi_{s}-\phi_{e}-E_{0,1}^{\prime}\right) /(2 R T)}\right)} \\
& c_{5}^{s}=\frac{c_{5}+\epsilon\left(1-\alpha_{g}\right) k_{2} e^{F\left(\phi_{s}-\phi_{e}-E_{0,1}^{\prime}\right) /(2 R T)}\left(\left(c_{4} / \gamma_{5}\right)+\left(c_{5} / \gamma_{4}\right)\right)}{1+\epsilon\left(1-\alpha_{g}\right) k_{2}\left(\left(1 / \gamma_{5}\right) e^{-F\left(\phi_{s}-\phi_{e}-E_{0,1}^{\prime}\right) /(2 R T)}+\left(1 / \gamma_{4}\right) e^{F\left(\phi_{s}-\phi_{e}-E_{0,1}^{\prime}\right) /(2 R T)}\right)}
\end{aligned}
$$

where $\gamma_{4}=D_{4} / d$ and $\gamma_{5}=D_{5} / d$. Similar expressions can be derived for the negative electrode reactants.

The overpotentials in the positive and negative electrodes, $\eta_{1}$ and $\eta_{2}$, respectively, are defined as follows:

$\eta_{1}=\phi_{s}-\phi_{e}-E_{0,1} ; \quad \eta_{2}=\phi_{s}-\phi_{e}-E_{0,2}$

where $E_{0,1}^{\prime}$ and $E_{0,2}^{\prime}$ are the open-circuit potentials for reactions (1) and (2), respectively, given by Nernst equations (changes in the proton concentration are neglected since they are small for a typical charge/discharge cycles):

$E_{0,1}^{\prime}=E_{0,1}+\frac{R T}{F}\left(\ln c_{5}-\ln c_{4}\right)$
$E_{0,2}^{\prime}=E_{0,2}+\frac{R T}{F}\left(\ln c_{3}-\ln c_{2}\right)$

The reaction constants are temperature dependent. They can be written in Arrhenius form as follows [28]:

$$
\begin{aligned}
k_{j} & =k_{\text {ref }, j} \exp \left(-\frac{\Delta G_{0, j}}{R}\left[\frac{1}{T_{\text {ref }}}-\frac{1}{T}\right]\right) \\
& =k_{\text {ref } j} \exp \left(\frac{n F E_{0, j}}{R}\left[\frac{1}{T_{\text {ref }}}-\frac{1}{T}\right]\right)
\end{aligned}
$$

for $j=1,2 . \Delta G_{0, j}=-n F E_{0, j}$ is the standard Gibbs free energy change for the respective reaction and the constant $k_{\text {ref } j}$ is the values of $k_{j}$ at a reference temperature $T_{\text {ref. }}$.

The current density associated with the $\mathrm{O}_{2}$ evolution reaction (3), which takes place predominantly during charge at the positive electrode, is approximated by the Tafel relationship:

$\nabla \cdot \vec{j}_{\mathrm{O}_{2}}=a \epsilon\left(1-\alpha_{g}\right) j_{0, \mathrm{O}_{2}} \exp \left(\frac{F \beta_{\mathrm{O}_{2}} \eta_{\mathrm{O}_{2}}}{R T}\right)$

where $j_{0, O_{2}}$ is the $\mathrm{O}_{2}$ evolution exchange current density given by:

$$
\begin{aligned}
j_{0, \mathrm{O}_{2}}(T) & =j_{0, \mathrm{O}_{2}}\left(T_{\text {ref }}\right) \exp \left(-\frac{\Delta G_{0, \mathrm{O}_{2}}}{R}\left[\frac{1}{T_{\text {ref }}}-\frac{1}{T}\right]\right) \\
& =j_{\text {ref } \mathrm{O}_{2}} \exp \left(\frac{n F E_{0, \mathrm{O}_{2}}\left(T_{\text {ref }}\right)}{R}\left[\frac{1}{T_{\text {ref }}}-\frac{1}{T}\right]\right)
\end{aligned}
$$


Table 5

Default values of the constants related to the electrochemical reactions.

\begin{tabular}{lll}
\hline Symbol & Quantity & Size \\
\hline$k_{\text {ref,1 }}$ & Standard rate constant: reaction (1) & $3 \times 10^{-9} \mathrm{~m} \mathrm{~s}^{-1}[15]$ \\
$k_{\text {ref, } 2}$ & Standard rate constant: reaction (2) & $1.25 \times 10^{-7} \mathrm{~m} \mathrm{~s}^{-1 \mathrm{a}}$ \\
$j_{\mathrm{ref}, \mathrm{O}_{2}}$ & Oxygen evolution exchange current density & $1 \times 10^{-9} \mathrm{~A} \mathrm{~m}^{-2}[16]$ \\
$\beta_{\mathrm{O}_{2}}$ & Transfer coefficient: reaction (3) & $0.3[35]$ \\
$E_{1}^{0}$ & Standard potential: $\mathrm{V}(\mathrm{IV}) / \mathrm{V}(\mathrm{V})$ & $1.004 \mathrm{~V}$ vs. SHE [36] \\
$E_{2}^{0}$ & Standard potential: $\mathrm{V}(\mathrm{II}) / \mathrm{V}(\mathrm{III})$ & $-0.255 \mathrm{~V} \mathrm{vs.} \mathrm{SHE} \mathrm{[36]}$ \\
$E_{\mathrm{O}_{2}}^{0}$ & Standard potential: $\mathrm{H}_{2} \mathrm{O} / \mathrm{O}_{2}$ & $1.23 \mathrm{~V} \mathrm{vs.} \mathrm{SHE} \mathrm{[36]}$ \\
$c_{f}$ & Fixed-charge site (sulfonate) concentration & $1200 \mathrm{~mol} \mathrm{~m}^{-3}[37]$ \\
$z_{f}$ & Charge of fixed (sulfonate) sites & -1 \\
\hline
\end{tabular}

a Fitted parameter.

in which $j_{\text {ref, } \mathrm{O}_{2}}=j_{0, \mathrm{O}_{2}}\left(T_{\text {ref }}\right)$ and $\Delta G_{0, \mathrm{O}_{2}}=-4 F E_{0, \mathrm{O}_{2}}$ is the standard Gibbs free energy change. $\beta_{\mathrm{O}_{2}}$ is the transfer coefficient and $\eta_{\mathrm{O}_{2}}$ is the overpotential for the $\mathrm{O}_{2}$ evolution reaction:

$\eta_{\mathrm{O}_{2}}=\phi_{s}-\phi_{e}-E_{0, \mathrm{O}_{2}}$

where $E_{0, \mathrm{O}_{2}}$ is the standard potential.

All of the standard potentials above are functions of temperature. The measured temperature dependence for each can be found in [29]:

$E_{0,1}=E_{1}^{0}+1.5 \times 10^{-3} \times(T-298.15)$

$E_{0,2}=E_{2}^{0}-9 \times 10^{-4} \times(T-298.15)$

$E_{0, \mathrm{O}_{2}}=E_{\mathrm{O}_{2}}^{0}-8.5 \times 10^{-4} \times(T-298.15)$

where $E_{1}^{0}, E_{2}^{0}$ and $E_{\mathrm{O}_{2}}^{0}$ are the standard potentials at $T=298.15 \mathrm{~K}$ for reactions (1)-(3), respectively, given in Table 5. The total current density in the positive electrode used in Eqs. (8) and (9) is the sum of the redox reaction and $\mathrm{O}_{2}$ evolution current densities:

$\nabla \cdot \vec{j}=\nabla \cdot \vec{j}_{1}+4 \nabla \cdot \vec{j}_{\mathrm{O}_{2}}=j_{1}+j_{\mathrm{O}_{2}}$

where a simpler notation for the volumetric current densities $j_{1}$ and $j_{\mathrm{O}_{2}}$ associated with the two reactions (1) and (3), respectively, have been defined.

\subsection{Boundary and initial conditions}

It is assumed that there is no leakage of reactant or charge through the external surfaces of the cell (see Fig. 1), no crossover of vanadium species through the membrane and no heat loss. Similarly, protons cannot penetrate the carbon plates and electrons cannot penetrate the membrane. All of these conditions are enforced with a zero concentration, charge or heat flux across the respective surface or interface. Along the interfaces between the electrode and the current collector, the liquid velocity satisfies a no-slip condition, $\vec{u}=0$.

\section{Table 6}

Default values of the constants related to structure.

\begin{tabular}{lll}
\hline Symbol & Quantity & Size \\
\hline$h$ & Electrode height & $10 \mathrm{~cm}$ \\
$L_{t}$ & Carbon electrode thickness & $4 \mathrm{~mm}$ \\
$L_{w}$ & Carbon electrode width & $10 \mathrm{~cm}$ \\
$L_{m}$ & Membrane thickness & $180 \mu \mathrm{m}$ \\
$L_{c}$ & Carbon plate thickness & $6 \mathrm{~mm}$ \\
$\epsilon$ & Carbon electrode porosity & 0.68 \\
$d_{f}$ & Carbon electrode fibre diameter & $172 \mu \mathrm{m} \mathrm{[31]}$ \\
$d_{g}$ & Oxygen gas bubble diameter & $50 \mu \mathrm{m}$ \\
$L_{w}$ & Electrode width & $10 \mathrm{~cm}$ \\
$V_{T}$ & Electrolyte volume (half-cell) & $250 \mathrm{~mL}$ \\
$a$ & Specific surface area: electrode & $3 \times 10^{6} \mathrm{~m}^{-1 \mathrm{~b}}$ \\
\hline
\end{tabular}

${ }^{\text {a }}$ Measured.

b Estimated.
Table 7

Default initial and boundary values.

\begin{tabular}{lll}
\hline Symbol & Quantity & Value \\
\hline$T_{\text {ref }}$ & Reference temperature & $25^{\circ} \mathrm{C}$ \\
$T_{0}$ & Initial temperature & $25^{\circ} \mathrm{C}$ \\
$c_{3}^{0}$ & V(III) concentration at inlet & $1053 \mathrm{~mol} \mathrm{~m}^{-3}$ \\
$c_{2}^{0}$ & V(II) concentration at inlet & $27 \mathrm{~mol} \mathrm{~m}^{-3}$ \\
$c_{4}^{0}$ & V(IV) concentration at inlet & $1053 \mathrm{~mol} \mathrm{~m}^{-3}$ \\
$c_{5}^{0}$ & V(V) concentration at inlet & $27 \mathrm{~mol} \mathrm{~m}^{-3}$ \\
$c_{d}^{0}$ & Water concentration at inlets & $4.2 \times 10^{3} \mathrm{~mol} \mathrm{~m}^{-3}$ \\
$p_{\text {out }, c}$ & Negative electrode outlet pressure & $300 \mathrm{kPa}^{0}$ \\
$p_{\text {out }, a}$ & Positive electrode outlet pressure & $300 \mathrm{kPa}^{-1}$ \\
$Q_{c}$ & Negative electrode volumetric flow rate & $1 \mathrm{~mL} \mathrm{~s}^{-1}$ \\
$Q_{a}$ & Positive electrode volumetric flow rate & $1 \mathrm{~mL} \mathrm{~s}^{-1}$ \\
$I_{\text {appl }}$ & Applied current & $10 \mathrm{~A}$ \\
\hline
\end{tabular}

The pressure is subject to a Neumann condition at the external surfaces, $\nabla p \cdot \vec{n}=0$, except at the inlets and outlets. At the outlets, the flow is considered to be fully developed, so that the reactant diffusive fluxes are prescribed zero values, $\nabla c_{i} \cdot \vec{n}=0$. Bubbles flow outwards with the oxygen bubble velocity, $\vec{u}_{\mathrm{g}}$ and the pressure satisfies a pressure outlet condition, $p=p_{\text {out }}$. At the inlets, the reactants enter with a prescribed bulk velocity and concentrations that depend on the pump rate, while the electrolyte is assumed to be
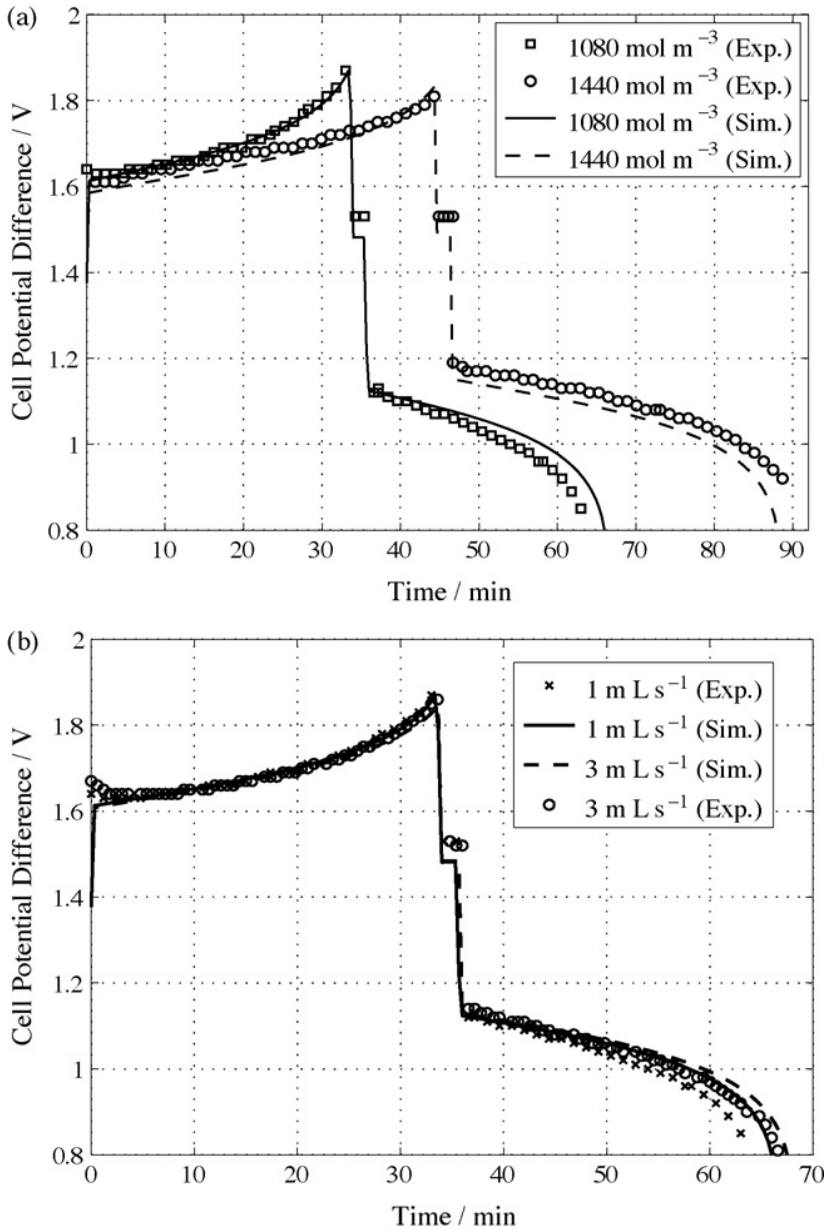

Fig. 2. Simulated and experimentally obtained cell voltage, $E_{\text {cell }}$ curves during charge/discharge at (a) two different concentrations of $c_{3}^{0}=c_{4}^{0}=1080 \mathrm{~mol} \mathrm{~m}^{-3}$ and $c_{3}^{0}=c_{4}^{0}=1440 \mathrm{~mol} \mathrm{~m}^{-3}$ at a flow rate of $Q=1 \mathrm{~mL} \mathrm{~s}^{-1}$ and (b) two different flow rates of $Q=1 \mathrm{~mL} \mathrm{~s}^{-1}$ and $Q=3 \mathrm{~mL} \mathrm{~s}^{-1}$ at a concentration of $c_{3}^{0}=c_{4}^{0}=1080 \mathrm{~mol} \mathrm{~m}^{-3}$. For all cases $I_{\mathrm{appl}}=10 \mathrm{~A}, d_{g}=50 \mu \mathrm{m}$ and $T_{0}=298 \mathrm{~K}$. The other parameter values are given in Tables 2, 4-7. 


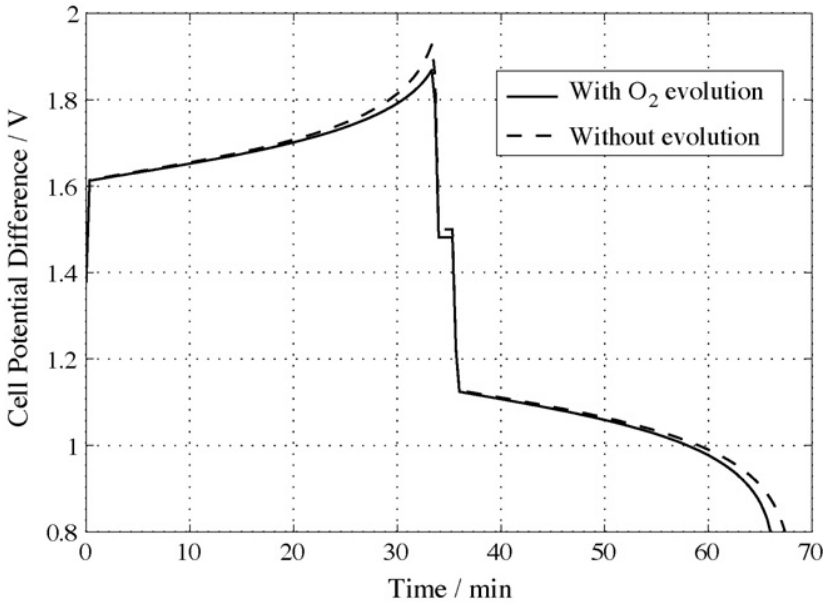

Fig. 3. A comparison between simulated cell voltage, $E_{\text {cell }}$ curves with and without $\mathrm{O}_{2}$ evolution at $c_{3}^{0}=c_{4}^{0}=1080 \mathrm{~mol} \mathrm{~m}^{-3}, I_{\mathrm{appl}}=10 \mathrm{~A}, Q=1 \mathrm{~mL} \mathrm{~s}^{-1}, d_{g}=50 \mu \mathrm{m}$ and $T_{0}=298 \mathrm{~K}$. The other parameter values are given in Tables $2-7$.
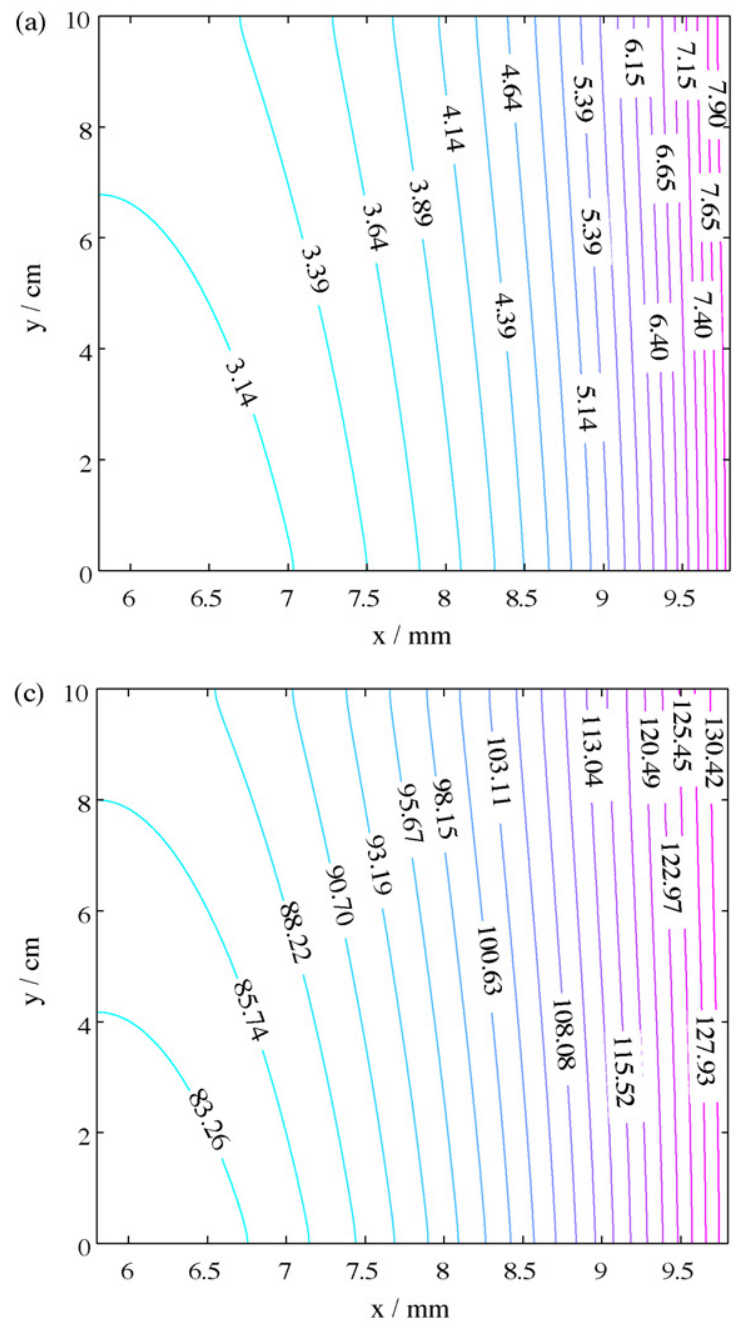

free of bubbles:

$c_{i}=c_{i}^{\text {in }}(t) ; \quad \phi_{g}=0 ; \quad \vec{u}_{l}=\left(0, v_{\text {in }}\right)$

Concentrations at the inlet boundaries vary with time depending on the movement of the electrolyte solution through the electrode and pump. By conservation of volume, the volumetric flow rate at the outlet boundaries is $Q=v_{\text {in }} \in A_{\text {out }}$, where $A_{\text {out }}=L_{t} L_{w}$ is the cross-sectional area of the outlet/inlet boundaries, $L_{t}$ is the electrode thickness and $L_{w}$ is the electrode width (Table 6). The inlet concentrations are approximated from the following mass balance, which assumes instantaneous mixing and negligible reaction in the reservoir of volume $V$ :

$\frac{d c_{i}^{\mathrm{in}}}{\mathrm{d} t}=\frac{Q}{V}\left(\frac{1}{L_{t}} \int_{y=h} c_{i} \mathrm{~d} x-c_{i}^{\mathrm{in}}\right) ; \quad c_{i}^{\mathrm{in}}(0)=c_{i}^{0}$

The integral on the right-hand side is the average concentration of species $i$ at the outflow boundaries and $c_{i}^{0}$ is the initial concentration of species $i$. The total volume of electrolyte on each side of the battery, $V_{T}$, is the sum of the electrode and the reservoir volumes, $\epsilon h A_{\text {out }}$ and $V$, respectively. It is assumed that the volume in the pipes is negligible.
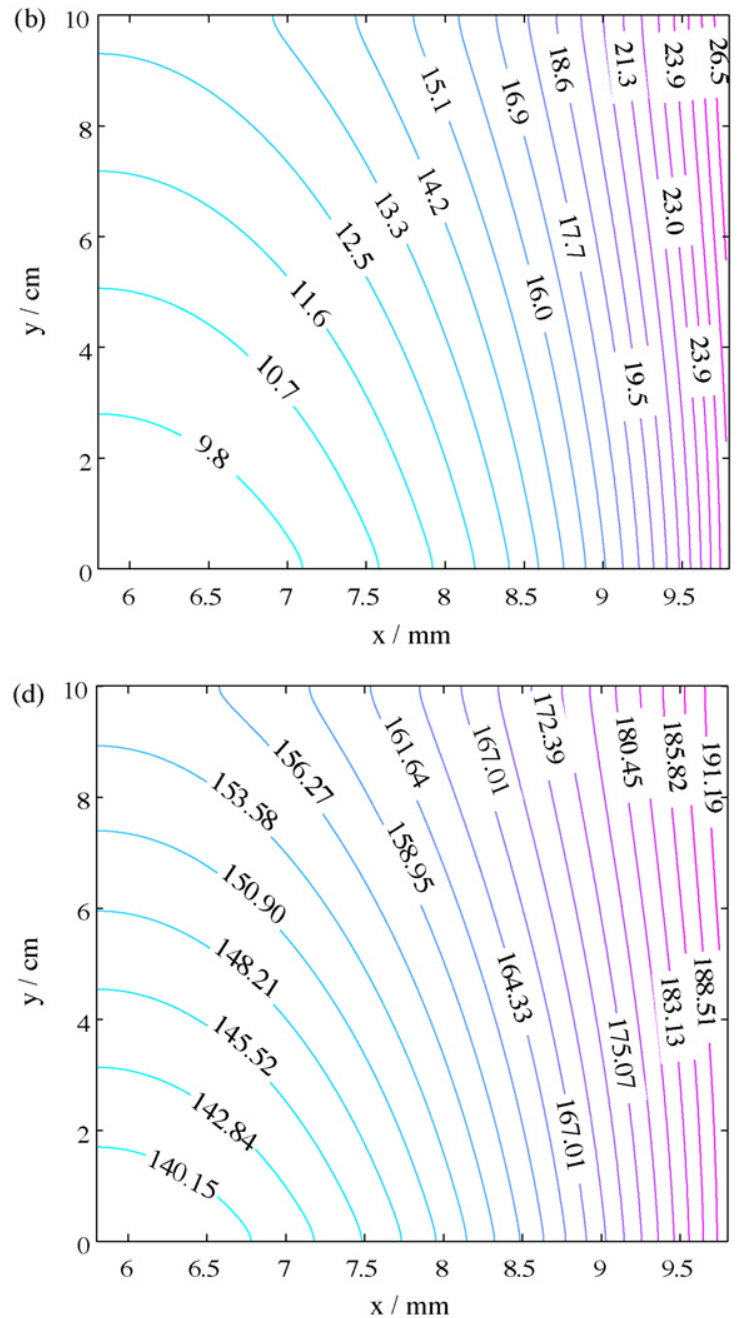

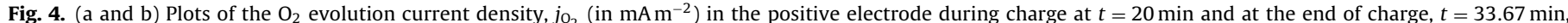

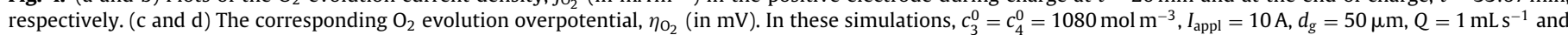

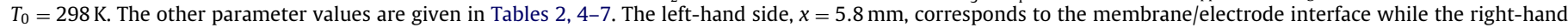
side, $x=9.8 \mathrm{~mm}$, corresponds to the electrode/current collector interface. 
During charge, the current is assumed to enter uniformly through the carbon plates:

$-\sigma_{c} \nabla \phi_{s} \cdot \vec{n}=\left\{\begin{array}{cl}\frac{I_{\mathrm{appl}}}{a} ; & \text { positive electrode } \\ -\frac{I_{\mathrm{appl}}}{a} ; & \text { negative electrode }\end{array}\right.$

where $I_{\text {appl }}$ is the applied current and $a$ is the surface area of the current collector. For discharge conditions the signs are reversed. The use of electronically conductive carbon feeders with a large cross-sectional justifies the assumption of a uniform current at the back edges of the feeders. This assumption is further justified by the presence of the highly conductive copper plates between the carbon feeders and electrical connections.

The initial conditions are as follows:

$T=T_{0} ; \quad c_{i}=c_{i}^{0} ; \quad \phi_{s}=E_{0,1}^{\prime} ; \quad \phi_{e}=0 ; \quad$ positive electrode

$T=T_{0} ; \quad c_{i}=c_{i}^{0} ; \quad \phi_{s}=E_{0,2}^{\prime} ; \quad \phi_{e}=0 ; \quad$ negative electrode

The initial and boundary values are given in Table 7 .

\subsection{Numerical details and parameters}

The default values for parameters used in the simulations are given in Tables 2, 4-7 The electrical conductivity of the carbon plates was taken from the data sheet provided by Entegris, whereas
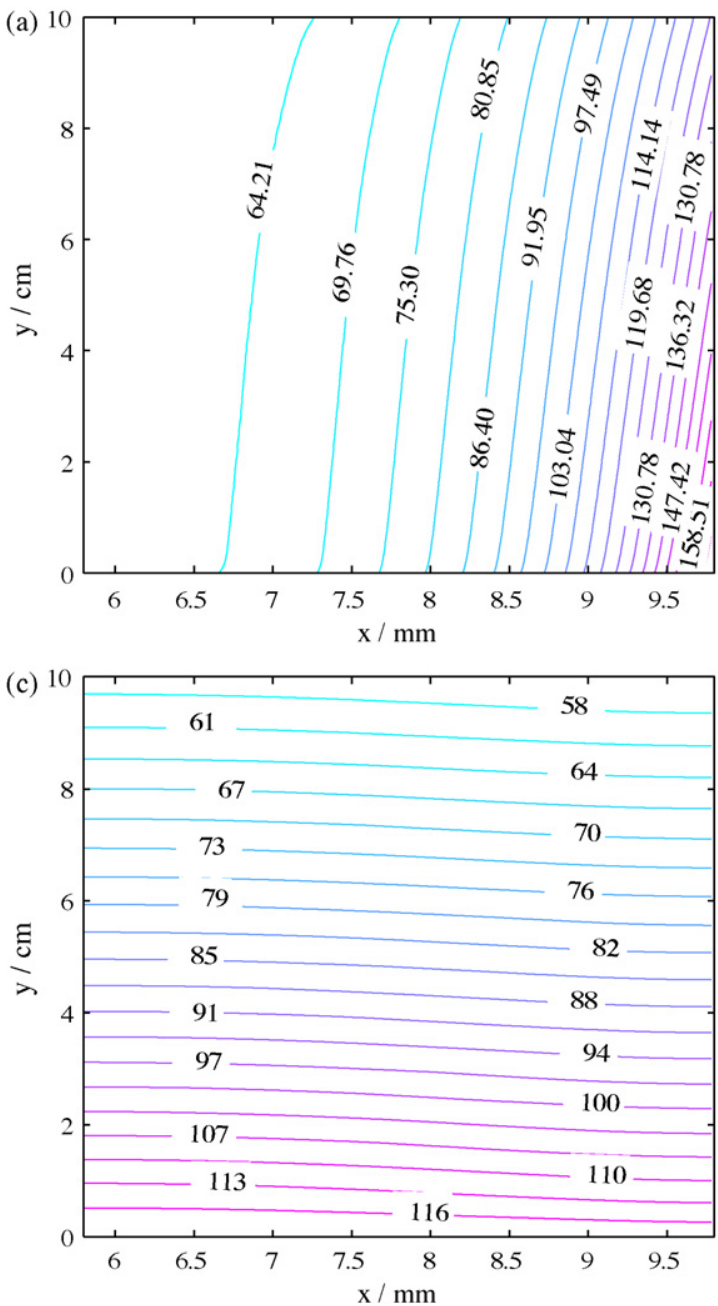

the thermal properties (not supplied) were estimated by the values for carbon. Sigratherm GFA5 were used for the porous carbon electrodes and Nafion ${ }^{\circledR}$ for the membrane. Most of the values have been discussed in detail elsewhere $[10,13]$. Values for the electrolyte were based on water, in the absence of data for the electrolyte. The value of the specific heat capacity of the membrane was also estimated by the value for water (since the bulk of the membrane is liquid water). In the membrane, the only form of heat transport is conduction while the ohmic heating in the electrolyte solution in the electrodes is assumed to be based only on the term containing $\sigma_{e}^{\text {eff }}$ in Eq. (8), which would be expected to be the main contributor. This permits a simpler form for the corresponding $Q_{k}$ value (Table 3).

The average pore diameter of the porous carbon foam or felt electrodes is typically in the range $100-800 \mu \mathrm{m}$ [30], with a value of around $150 \mu \mathrm{m}$ [31,32] for Sigratherm electrodes. The bubble diameter depends on various factors, including the electrolyte composition, current density and flow rate. A wide range of diameter values has been reported [19,33,34], from 25 to $100 \mu \mathrm{m}$. In this work, a range of bubble diameter is considered.

The rate constant for the reaction at the positive electrode was determined by Gattrel et al. [15], while the rate constant for the negative electrode reaction was derived through a fitting procedure as in $[10,13]$; the value was adjusted until the desired fit to the experimental charge-discharge curve in the base case (described below)
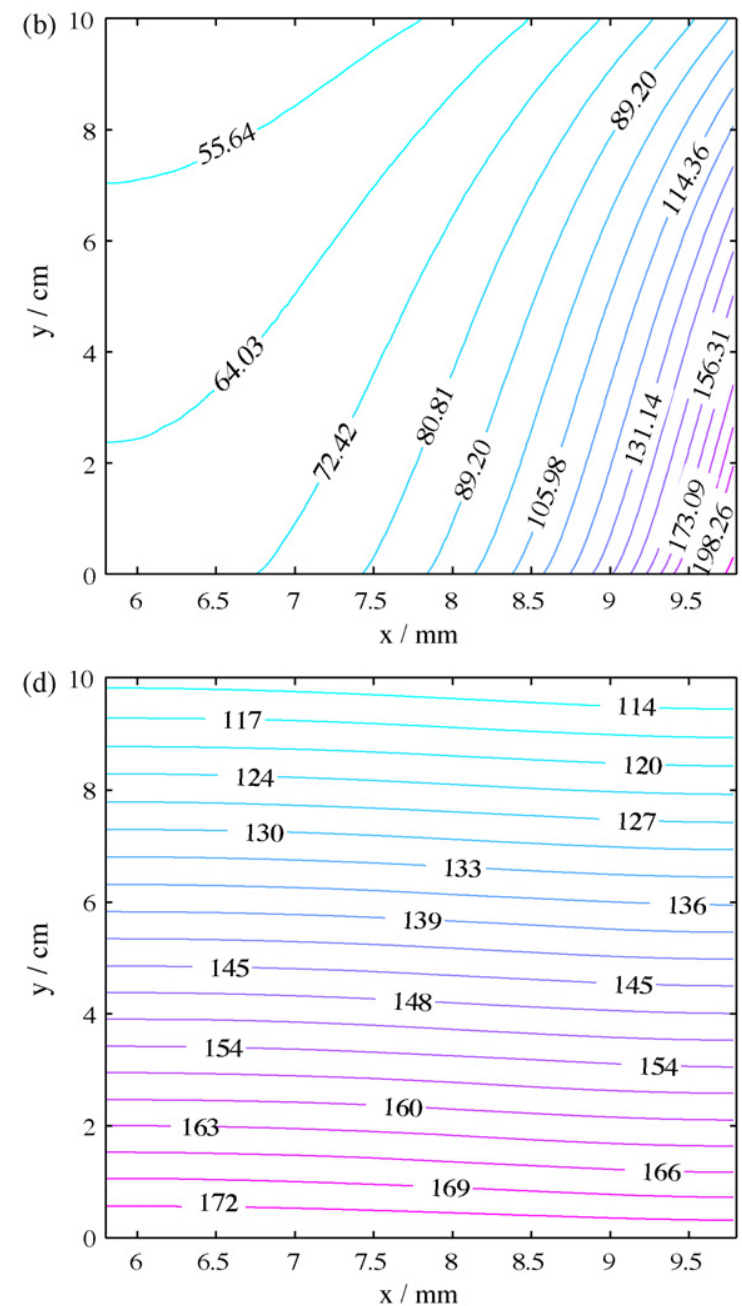

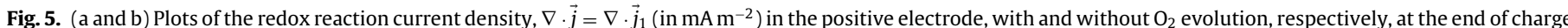

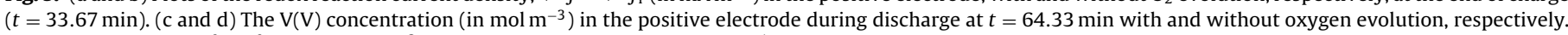
In these calculations, $c_{3}^{0}=c_{4}^{0}=1080 \mathrm{~mol} \mathrm{~m}^{-3}, I_{\mathrm{appl}}=10 \mathrm{~A}, d_{g}=50 \mu \mathrm{m}, Q=1 \mathrm{~mL} \mathrm{~s}^{-1}$ and $T_{0}=298 \mathrm{~K}$. The other parameter values are given in Tables $2,4-7$. 
was achieved. The values used for the reference exchange current density, $j_{\text {ref, } \mathrm{O}_{2}}$ and the transfer coefficient, $\beta_{\mathrm{O}_{2}}$ were determined by Saleh [16] for $\mathrm{O}_{2}$ evolution on bare reticulated vitreous carbon. These values were calculated by fitting a rather simplified model to experimental data. Given the possible inaccuracies in these values, a sensitivity analysis in $j_{\text {ref, } \mathrm{O}_{2}}$ was performed and the results are presented in Section 4.5. These results also provide an indication of the characteristics of $\mathrm{O}_{2}$ evolution on non-RVC electrodes.

The model was solved using the COMSOL Multiphysics ${ }^{\circledR}$ package, which is based on the finite-element method. A quadratic basis was used in all of the simulations, together with a minimum of 2548 elements and a maximum of 7256 elements, based on grid dependency checks that compared the times to SOC for successively more refined meshes. This measure was found to be a good indicator of convergence. The relative error tolerance was set to $1 \times$ $10^{-6}$. The base-case calculation (a charge-discharge of $63 \mathrm{~min}$ with $Q=1 \mathrm{~mL} \mathrm{~s}^{-1}, c_{3}^{0}=c_{4}^{0}=1080 \mathrm{~mol} \mathrm{~m}^{-3}, T_{0}=298 \mathrm{~K}, d_{g}=50 \mu \mathrm{m}$ and $I_{\text {appl }}=10 \mathrm{~A}$ ) took $33 \mathrm{~min}$ on a Viglen Intel(R) Xeon(R) CPU, 64-bit desktop with $4 \mathrm{~Gb}$ RAM.

\section{Results and discussion}

The state of charge in the calculations was estimated from the residual $\mathrm{V}(\mathrm{IV})$ concentration, $1-c_{4, \mathrm{av}} / c_{4}^{0}$. The quantity $c_{4, \mathrm{av}}$ is the average $\mathrm{V}(\mathrm{IV})$ concentration in the positive half-cell (including
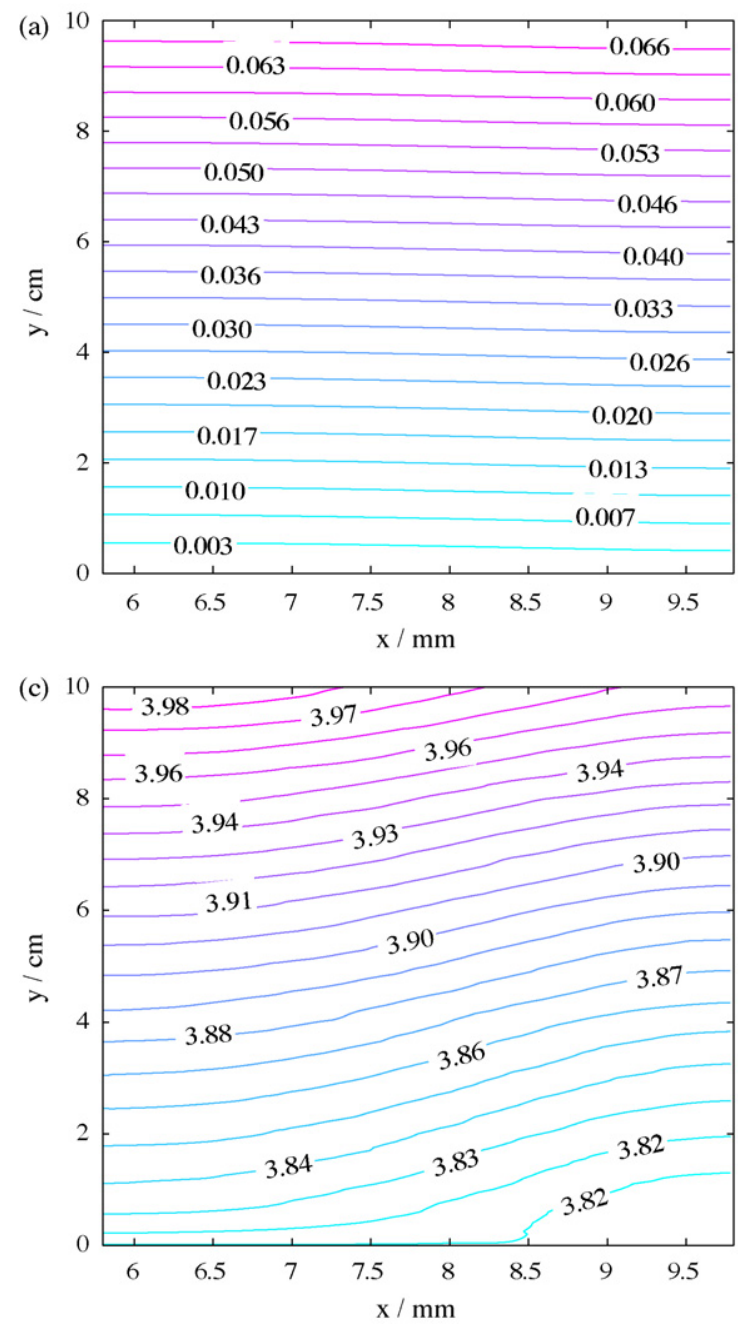

both the electrode and reservoir volumes [13]). The cell potential difference was calculated as the difference between the electronic potentials along the intersections between the carbon plates and electrodes. This approximates the experimental measurement from the potential difference across the dummy cell, i.e., with conditions pertaining to the outlets. At the end of the charge period, $2 \mathrm{~min}$ of operation at zero current followed by discharge were simulated in each calculation.

\subsection{Validation and the effects of oxygen evolution}

Simulated and experimental cell voltage, $E_{\text {cell }}$ curves for two concentrations, $c_{3}^{0}=c_{4}^{0}=1080 \mathrm{~mol} \mathrm{~m}^{-3}$ and $c_{3}^{0}=c_{4}^{0}=$ $1440 \mathrm{~mol} \mathrm{~m}^{-3}$, with an electrolyte flow rate of $Q=1 \mathrm{~mL} \mathrm{~s}^{-1}$ and for two flow rates, $Q=1 \mathrm{~mL} \mathrm{~s}^{-1}$ and $Q=3 \mathrm{mLs}^{-1}$, with a concentration of $c_{3}^{0}=c_{4}^{0}=1080 \mathrm{~mol} \mathrm{~m}^{-3}$ are shown in Fig. 2(a) and (b), respectively. The other parameter values are given in Tables 2, 4-7 The model captures the trends well, both sets of results showing an increase in the cell potential difference at the end of charge for the lower flow rate and concentration and an increase in the charge efficiency as the flow rate and concentration are increased as a result of greater spatial uniformity of the reactants at the equivalent SOC, as discussed in detail elsewhere [13]. As the concentration increases from $c_{3}^{0}=c_{4}^{0}=1080 \mathrm{~mol} \mathrm{~m}^{-3}$ to $c_{3}^{0}=c_{4}^{0}=1440 \mathrm{~mol} \mathrm{~m}^{-3}$, the simulated charge efficiencies

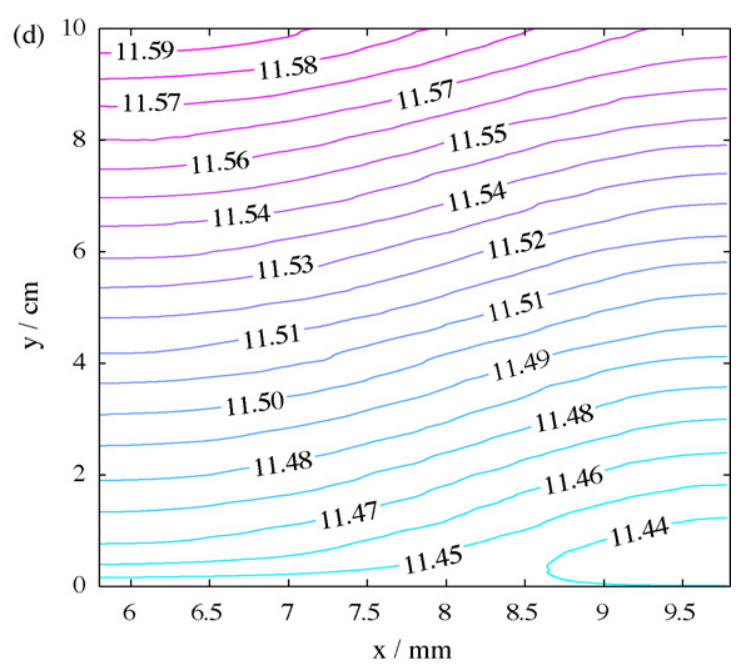

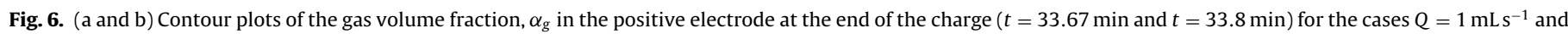

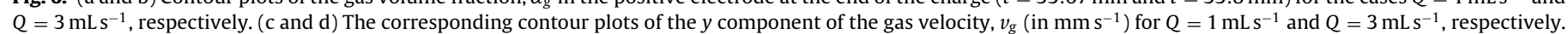
In these simulations, $c_{3}^{0}=c_{4}^{0}=1080 \mathrm{~mol} \mathrm{~m}^{-3}, I_{\mathrm{appl}}=10 \mathrm{~A}, d_{g}=50 \mu \mathrm{m}$ and $T_{0}=298 \mathrm{~K}$. The other parameter values are given in Tables $2,4-7$. 
increase from $88.42 \%$ to $91.2 \%$ and the corresponding experimental efficiencies increase from $85.1 \%$ to $93.1 \%$. Likewise, increasing the flow rate from $Q=1 \mathrm{~mL} \mathrm{~s}^{-1}$ to $Q=3 \mathrm{~mL} \mathrm{~s}^{-1}$, increases the simulated and the experimental charge efficiencies to $91.8 \%$ and $92.6 \%$, respectively. The charge time (to the equivalent SOC) for $Q=1 \mathrm{mLs}^{-1}$ was $33.67 \mathrm{~min}$, while for $Q=3 \mathrm{mLs}^{-1}$ it was estimated to be $33.8 \mathrm{~min}$ and for $c_{3}^{0}=c_{4}^{0}=1440 \mathrm{~mol} \mathrm{~m}^{-3}$ to be $44.53 \mathrm{~min}$. The latter two theoretical times were a good fit to the experimental times, in which the state of charge was measured by monitoring the open-circuit potential.

The effects of $\mathrm{O}_{2}$ evolution on the charge/discharge behaviour are illustrated in Fig. 3, which shows the cell voltage, $E_{\text {cell }}$ curves for the base-case parameters both with and without $\mathrm{O}_{2}$ evolution included in the model. The charge time is $33.67 \mathrm{~min}$ in each case, resulting in different SOC values at the end of charge for the two cases. The effects $\mathrm{O}_{2}$ evolution are most strongly felt towards the end of charge, when the cell potential difference in the case including $\mathrm{O}_{2}$ evolution decreases relative to the case without $\mathrm{O}_{2}$ evolution. During discharge, the presence of $\mathrm{O}_{2}$ evolution reduces the time to discharge and, consequently, reduces the Coulombic (charge) efficiency of the battery; the charge efficiency is $88 \%$ with evolution and $94.15 \%$ without evolution.

Fig. 4(a) and (b) shows the distributions of the $\mathrm{O}_{2}$ evolution current density, $j_{\mathrm{O}_{2}}=4 \nabla \cdot \vec{j}_{\mathrm{O}_{2}}$ (in $\mathrm{mAm}^{-2}$ ) during charge, $t=20$ $\mathrm{min}$, and at the end of charge, $t=33.67 \mathrm{~min}$. The left-hand side of the plots, $x=5.8 \mathrm{~mm}$, corresponds to the membrane/positive electrode interface while the right-hand side, $x=9.8 \mathrm{~mm}$ corresponds to the positive electrode/current collector interface. The bottom line, $y=0 \mathrm{~cm}$, corresponds to the inlet surface and the upper line, $y=10 \mathrm{~cm}$, corresponds to the outlet. The maximum at both times occurs at the intersection between the outlet and the current collector ( $x=9.8 \mathrm{~mm}, y=10 \mathrm{~cm}$ ) while the minimum occurs at the intersection between the inlet and the membrane $(x=5.8 \mathrm{~mm}$, $y=0 \mathrm{~cm}$ ). The $\mathrm{O}_{2}$ current density increases along any vertical line as the outlet is approached and along any horizontal line as the current collector approached. The corresponding distributions of the $\mathrm{O}_{2}$ evolution overpotential, $\eta_{\mathrm{O}_{2}}$ (in $\mathrm{mV}$ ) are given in Fig. 4 (c) and (d). There is a close link between the $\mathrm{O}_{2}$ evolution current density, $j_{\mathrm{O}_{2}}$ and the $\mathrm{O}_{2}$ evolution overpotential, $\eta_{\mathrm{O}_{2}}$, their distributions resembling a similar pattern during charge. It appears that the $\mathrm{O}_{2}$ evolution current density is controlled by the $\mathrm{O}_{2}$ evolution overpotential, which is controlled primarily by the electronic potential, $\phi_{s}$, and the open-circuit potential $E_{0, \mathrm{O}_{2}}$, as given in Eq. (24).

Fig. 5(a) and (b) shows the profiles of the redox reaction current density, $\nabla \cdot \vec{j}=j_{1}$ (in $\mathrm{mA} \mathrm{m}^{-2}$ ) with and without $\mathrm{O}_{2}$ evolution, respectively, at the end of charge in the positive electrode $(t=$ $33.67 \mathrm{~min}$ ). In both cases, the maximum occurs at the intersection between the inlet and the current collector surface $(x=9.8 \mathrm{~mm}$, $y=0 \mathrm{~cm})$. The maximum value of the total current density with evolution is approximately $20 \%$ lower than its maximum value in the case without evolution. This is clearly due to the presence of the $\mathrm{O}_{2}$ evolution reaction, which consumes a portion of the applied current and reduces the value of $j_{1}$ by a factor of $\alpha_{g}$. The state of charge at $t=33.67 \mathrm{~min}$ is, therefore, higher in the case without $\mathrm{O}_{2}$ evolution, leading to a longer time required to reach full discharge (consume the $\mathrm{V}(\mathrm{V})$ in the positive electrode and $\mathrm{V}(\mathrm{II})$ in the negative electrode). Consequently, the charge efficiency is higher. Fig. 5(c) and (d) shows the $V(V)$ concentration profiles at $t=64.33$ min during discharge, with clearly higher concentrations in the case without $\mathrm{O}_{2}$ evolution.

\subsection{Influence of electrolyte flow rate}

Contour plots of the $\mathrm{O}_{2}$ volume fraction, $\alpha_{g}$ in the positive electrode at the end of charge (to an equivalent $S O C$ ) for two different flow rates, $Q=1 \mathrm{mLs}^{-1}$ and $Q=3 \mathrm{~mL} \mathrm{~s}^{-1}$ are shown in Fig. 6(a) and (b), respectively. The other parameter values are given in Tables 2, 4-7 The increase in the flow velocity by a factor of three reduces the volume fraction of gas by a factor of three The value of $\alpha_{g}$ increases as the height above the inlet surface increases along any vertical line. The assumption of an inlet free of bubbles maintains a zero value of $\alpha_{g}$ at the inlet, $y=0$. The degree of variation of the gas volume fraction in the horizontal direction is minimal since the flow is convection dominated in the vertical direction. The maximum value in the gas volume fraction, attained at the outlet surface, is approximately $68 \%$ lower at the higher flow rate, $Q=3 \mathrm{~mL} \mathrm{~s}^{-1}$. A decrease in the gas volume fraction, with other conditions fixed, would decrease the slip velocity, $\vec{u}_{\text {slip }}=\left(u_{\text {slip }}, v_{\text {slip }}\right)$ given by Eq. (5), with the pressure gradient given by Eq. (4)[10]. As the gas volume fraction decreases, the Kozeny-Carman factor in the relative permeability in Eq. (4) increases, resulting in a higher liquid velocity and a smaller value of $\nabla p$; the reduced volume of liquid lowers the permeability and increases pressure gradients. In Fig. 6(c), therefore, the $y$ component of the gas velocity, $v_{g}$ is $11.8 \%$ higher than the initial liquid velocity $\left(3.57 \mathrm{~mm} \mathrm{~s}^{-1}\right)$, while in Fig. 6 (d), $v_{g}$ is only $8.2 \%$ higher than the initial liquid velocity $\left(10.71 \mathrm{~mm} \mathrm{~s}^{-1}\right)$, i.e., the departure of the gas velocity from the liquid velocity (the slip velocity) is relatively smaller at the higher flow
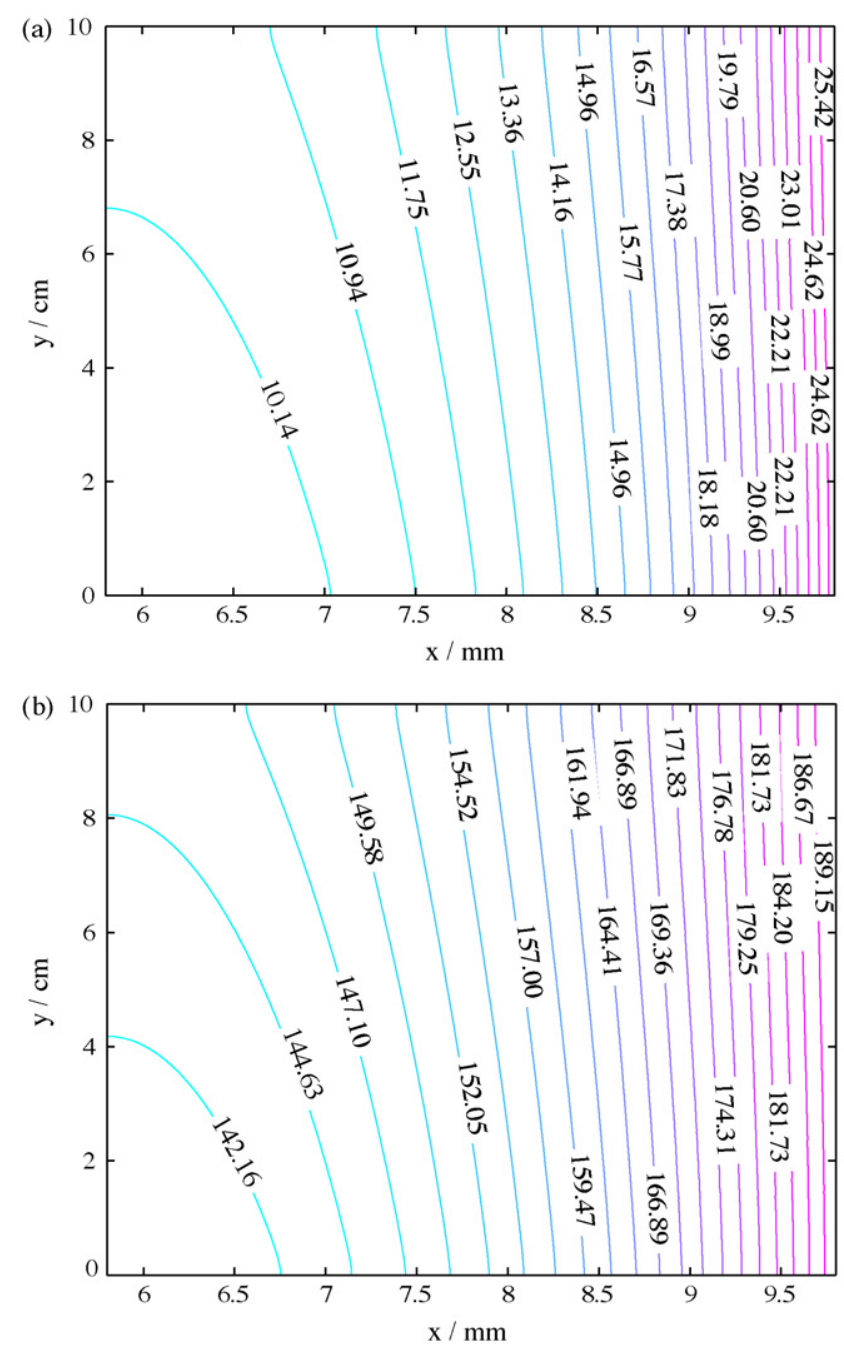

Fig. 7. (a) Contour plots of the $\mathrm{O}_{2}$ evolution current density, $j_{\mathrm{O}_{2}}$ (in $\mathrm{mAm}{ }^{-2}$ ) and (b) the corresponding $\mathrm{O}_{2}$ evolution overpotential, $\eta_{\mathrm{O}_{2}}$ (in $\mathrm{mV}$ ) at the end of the charge in the positive electrode for $Q=3 \mathrm{mLs}^{-1}$. In these simulations, $c_{3}^{0}=c_{4}^{0}=$ $1080 \mathrm{~mol} \mathrm{~m}^{-3}, I_{\mathrm{appl}}=10 \mathrm{~A}, d_{g}=50 \mu \mathrm{m}$ and $T_{0}=298 \mathrm{~K}$. The other parameter values are given in Tables $2,4-7$ 

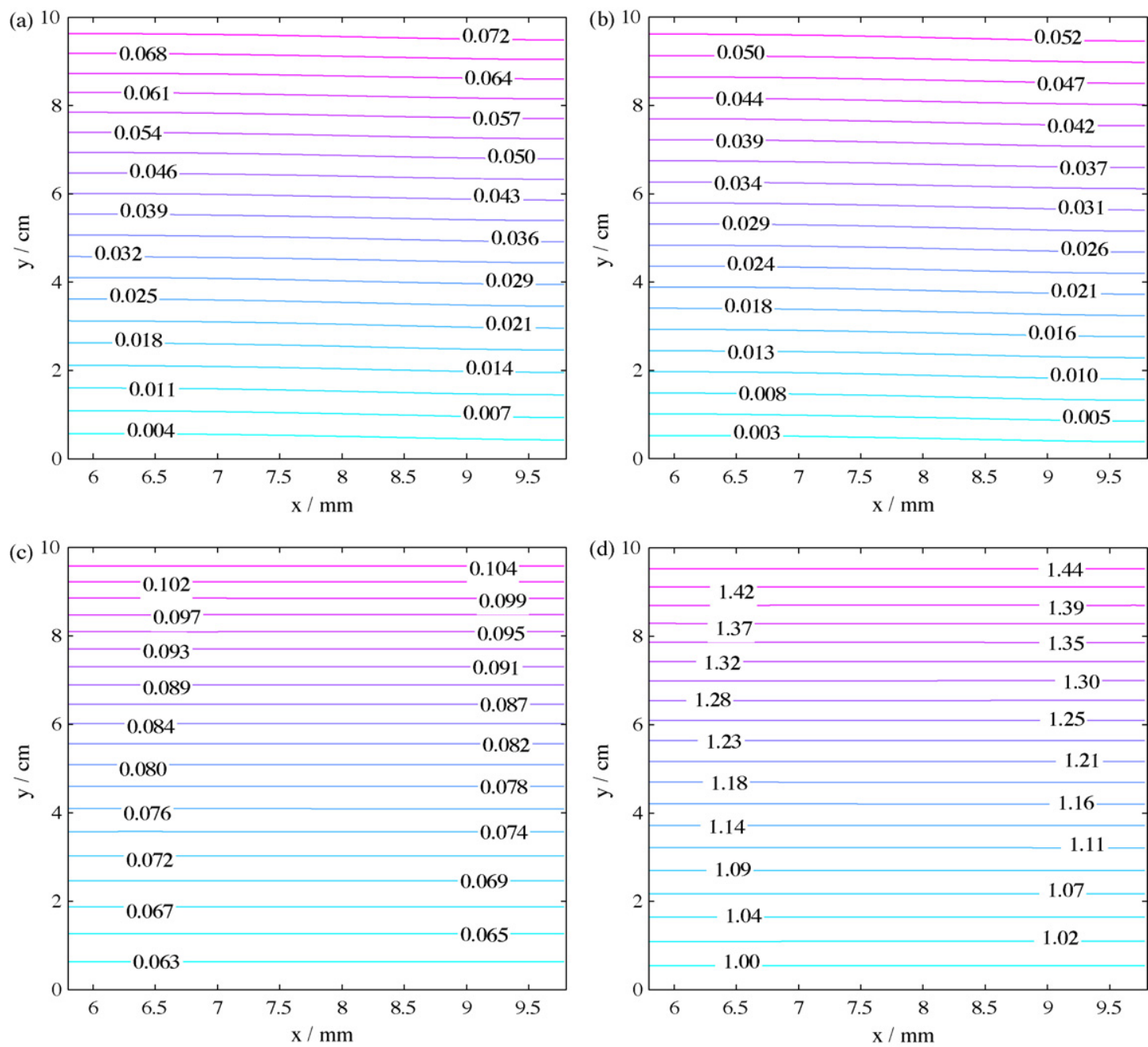

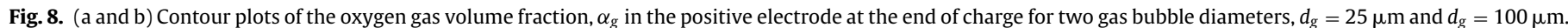

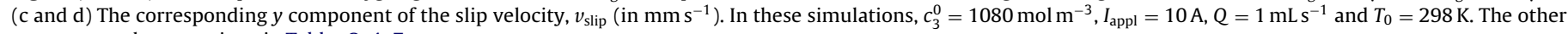
parameter values are given in Tables 2, 4-7.

rate. The increase in the liquid velocity, however, is the dominant effect, which leads to the much lower gas gas volume fraction for $Q=3 \mathrm{mLs}^{-1}$.

Fig. 7(a) and (b) shows contours of the $\mathrm{O}_{2}$ evolution current density, $j_{\mathrm{O}_{2}}$, and the $\mathrm{O}_{2}$ evolution overpotential, $\eta_{\mathrm{O}_{2}}$, respectively, at the end of charge ( $t=33.8 \mathrm{~min}$ ) for $Q=3 \mathrm{~mL} \mathrm{~s}^{-1}$ (to be compared with Fig. 4(b) and (d), respectively). The higher flow rate leads to a more even distribution of reactant and, consequently lower overpotential values. Thus, the $\mathrm{O}_{2}$ evolution rate is decreased (compared to Fig. 7 (a)). This leads to a further reduction in the $\mathrm{O}_{2}$ volume fraction, though this reduction is small in comparison to the reduction caused by the higher liquid velocity.

\subsection{Influence of bubble diameter}

The average (equivalent) diameter of the bubbles formed from gas evolution can range from 25 to $100 \mu \mathrm{m}$, depending on the operating conditions [19,33,34]. Simulations were performed using values of $d_{g}=25 \mu \mathrm{m}$ and $d_{g}=100 \mu \mathrm{m}$ (to an equivalent SOC) with other parameter values as in the base case in which $d_{g}=50 \mu \mathrm{m}$ (Figs. 4 and 5). Fig. 8(a) and (b) shows the distribution of the $\mathrm{O}_{2}$ volume fraction, $\alpha_{g}$ in the positive electrode at the end of charge ( $t \approx 33.7 \mathrm{~min}$ in all cases). As was the case for $d_{g}=50 \mu \mathrm{m}$, the value of $\alpha_{g}$ increases as the height above the inlet surface increases con- siderably along any vertical line, whereas its degree of variation in the horizontal direction is minimal. The maximum value of the gas fraction, $\alpha_{g}$, attained at the outlet, is decreased by approximately $27 \%$ as the bubble diameter increases from $d_{g}=25 \mu \mathrm{m}$ to $d_{g}=100 \mu \mathrm{m}$.

The lower gas volume fraction for the larger diameter is caused by a considerably greater slip velocity, as indicated by Fig. 8(c) and (d), which shows the $y$ component of the slip velocity, $v_{\text {slip }}$ for the two diameters. Eq. (5) suggests that the slip velocity increases with an increase in the bubble diameter, for a fixed pressure gradient. The gas velocity, which is the sum of the liquid and slip velocities is, therefore, increased. From a physical perspective, the drag force is proportional to surface area of the bubble (or $d_{g}^{2}$ ) and the buoyancy force is proportional to the bubble volume (or $d_{g}^{3}$ ). Larger bubbles, therefore, induce a higher slip velocity through an increased net force. The higher gas velocity removes the bubbles at a faster rate, thereby lowering the gas volume fraction.

\subsection{Influence of operating temperature}

Fig. 9(a) shows the simulated cell potential difference curves during a charge/discharge cycle for three operating temperatures, $T_{0}=288,298$ and $313 \mathrm{~K}$ for the aforementioned base case. The other parameter values are given in Tables 2, 4-7 In all three cases the 

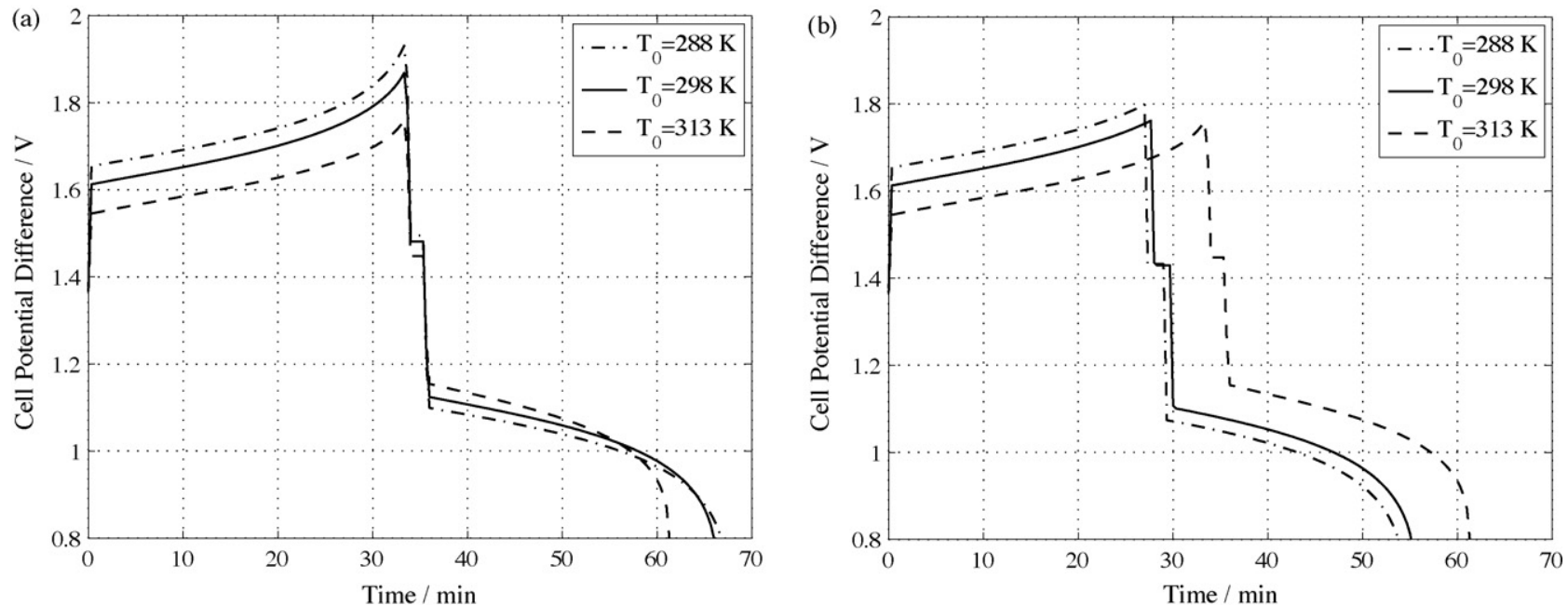

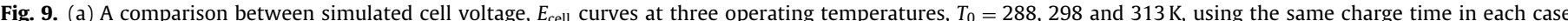

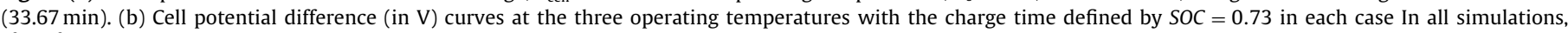
$c_{3}^{0}=c_{4}^{0}=1080 \mathrm{~mol} \mathrm{~m}^{-3}, I_{\mathrm{appl}}=10 \mathrm{~A}, Q=1 \mathrm{~mL} \mathrm{~s}^{-1}$ and $d_{g}=50 \mu \mathrm{m}$. The other parameter values are given in Tables $2,4-7$.
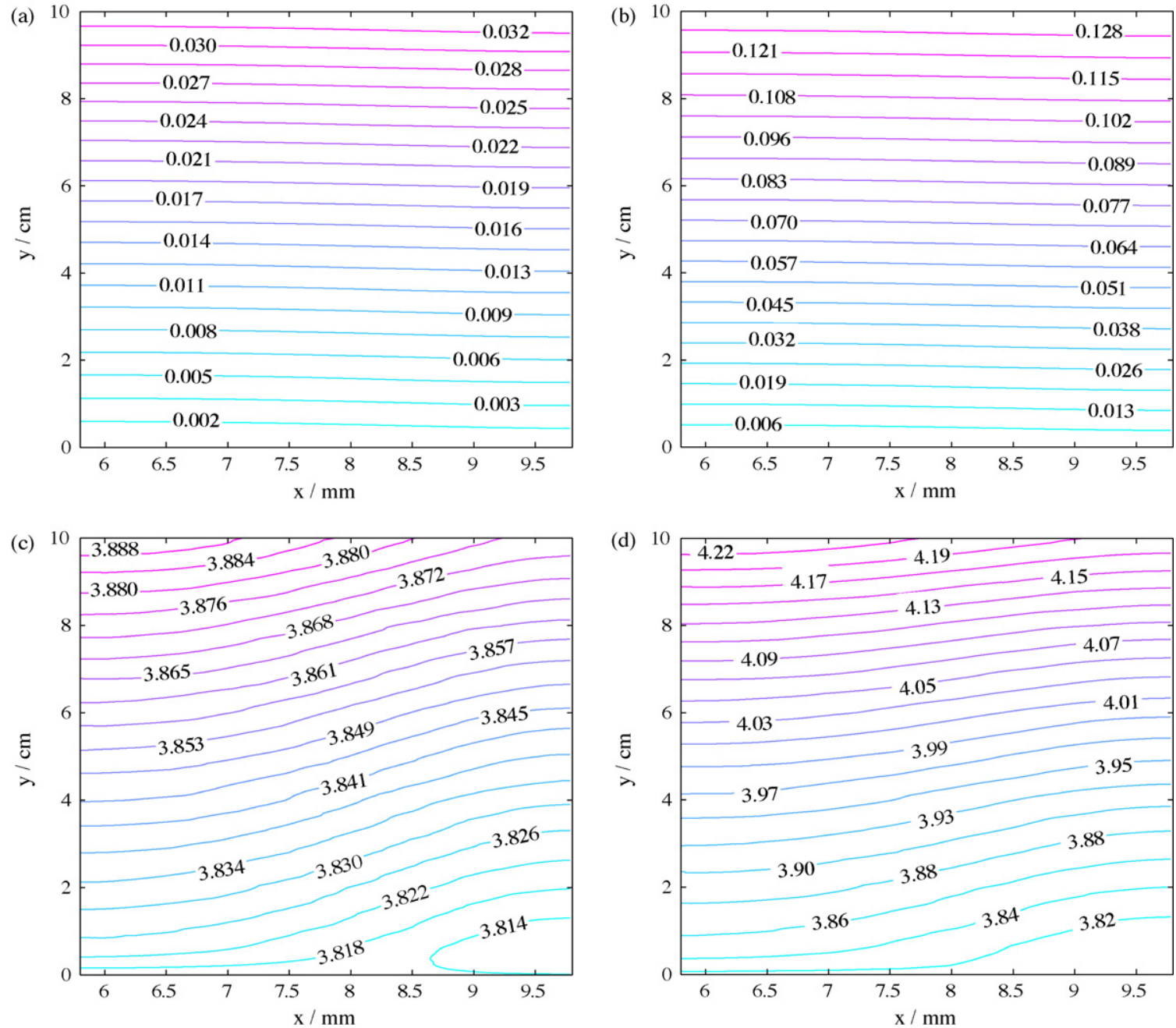

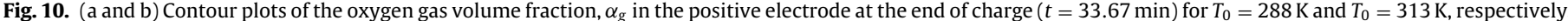

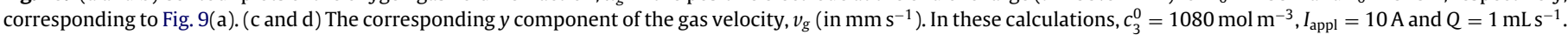
The other parameter values are given in Tables 2, 4-7. 
system is assumed to be adiabatic. In each case, charging was terminated at the same time of $33.67 \mathrm{~min}$. The state of charge was estimated to be $0.9,0.87$ and 0.73 from the lowest to the highest temperature, respectively. As the temperature increases, the cell potential difference decreases during charge and increases during discharge, i.e., the departure from the open-circuit voltage (OCV) decreases. The capacity of the battery (at the constant charge time) decreases markedly between $T_{0}=298 \mathrm{~K}$ and $T_{0}=313 \mathrm{~K}$, with only a small decrease between $T_{0}=288 \mathrm{~K}$ and $T_{0}=298 \mathrm{~K}$. The charge efficiency of the battery decreases from $92 \%$ at an operating temperature of $T_{0}=288 \mathrm{~K}$ to $77 \%$ at $T_{0}=313 \mathrm{~K}$.

The decreased deviation of the cell potential difference from OCV with increasing temperature is due to several factors [12]. The equilibrium potentials given by Eqs. (20) and (25) decrease in magnitude, for fixed initial concentrations of the reactants-the cell potential difference at $t \approx 0$ in Fig. 9 (a) decreases as the temperature is increased. An increased temperature increases the rate constants, $k_{i}$ given in Eq. (21). An increased reaction rate constant leads to an decrease in the magnitude of the overpotential, in the absence of other effects such as gas evolution, in order to maintain the (fixed) applied current, as is seen from the Butler-Volmer equations (17). Note that the potential-dependent exponential in the Butler-Volmer equations would tend to decrease with an increase in temperature, for a fixed potential, which would tend to require
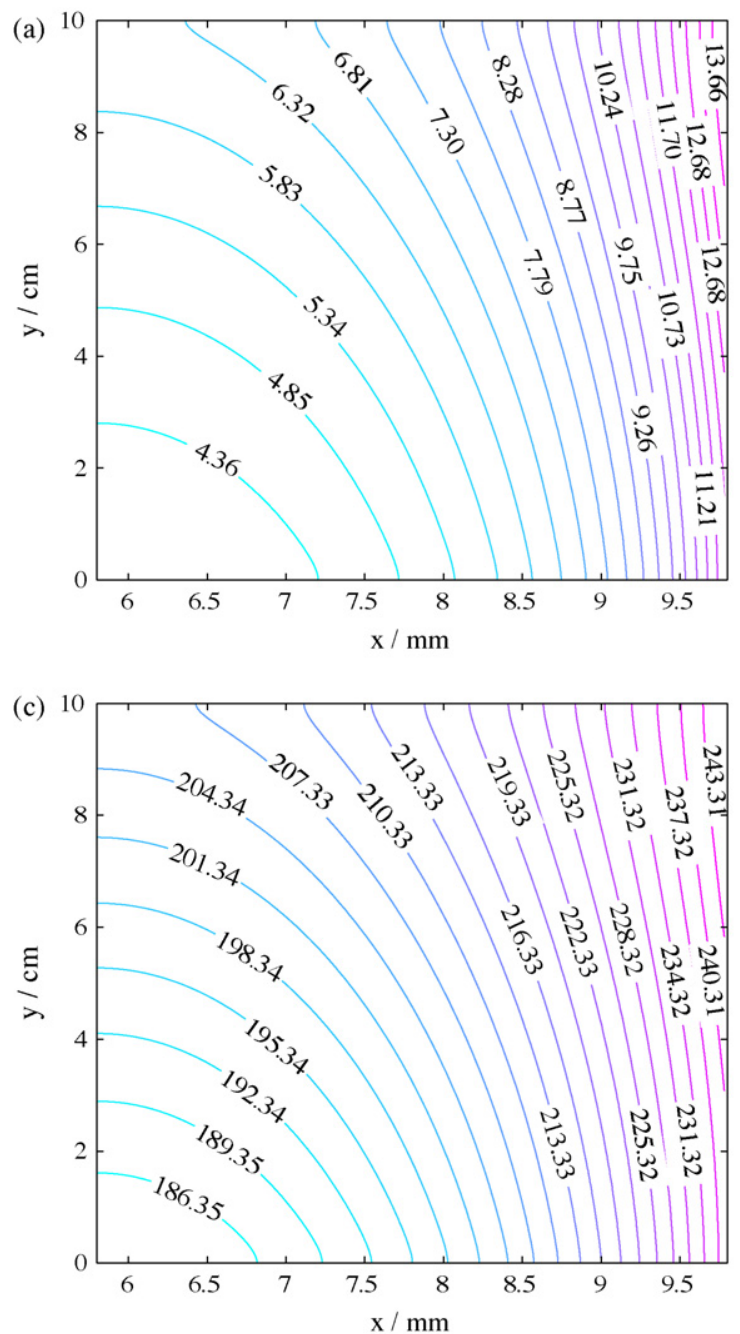

an increase in the magnitude of the overpotential. The increase in the reaction constant, however, dominates this effect due to the large activation energies in Eq. (21). With gas evolution included, an increase at a fixed current density in one or both of the rate constants for the two reactions (1) and (3) will, in the absence of other variations, lower the overpotentials $\eta_{\mathrm{O}_{2}}$ and $\eta_{1}$, which differ by the difference between the equilibrium potentials for the reactions: $\eta_{\mathrm{O}_{2}}=\eta_{1}+E_{0,1}^{\prime}-E_{0, \mathrm{O}_{2}}$.

Fig. 10(a) and (b) shows the gas volume fraction, $\alpha_{g}$ at the end of the charge time $(t=33.67 \mathrm{~min})$ for the two temperatures $T_{0}=288 \mathrm{~K}$ and $T_{0}=313 \mathrm{~K}$ (compared with Fig. 6(a)). The maximum in the volume fraction increases from approximately $3.2 \%$ to approximately $13 \%$ from the lower to the higher temperature. This is despite an increase in the gas velocity, the $y$ component of which, $v_{\mathrm{g}}$ is shown in Fig. 10(c) and (d) for the two temperatures $T_{0}=288 \mathrm{~K}$ to $T_{0}=313 \mathrm{~K}$, respectively, at the end of charge; the maximum in $v_{g}$ increases by $8.5 \%$ from $T_{0}=288 \mathrm{~K}$ to $T_{0}=313 \mathrm{~K}$.

The increase in the gas velocity is due to the increased gas volume fraction, which increases the slip velocity as described above. The increase in $\alpha_{g}$ is due to the increase in the value of the $\mathrm{O}_{2}$ evolution current density. Fig. 11(a) and (b) shows contours of the $\mathrm{O}_{2}$ evolution current density, $j_{\mathrm{O}_{2}}$ (in $\mathrm{mAm}^{-2}$ ) in the positive electrode at the end of charge $(t=33.67 \mathrm{~min})$. As the operating temperature increases from $T_{0}=288-313 \mathrm{~K}$, the maximum value
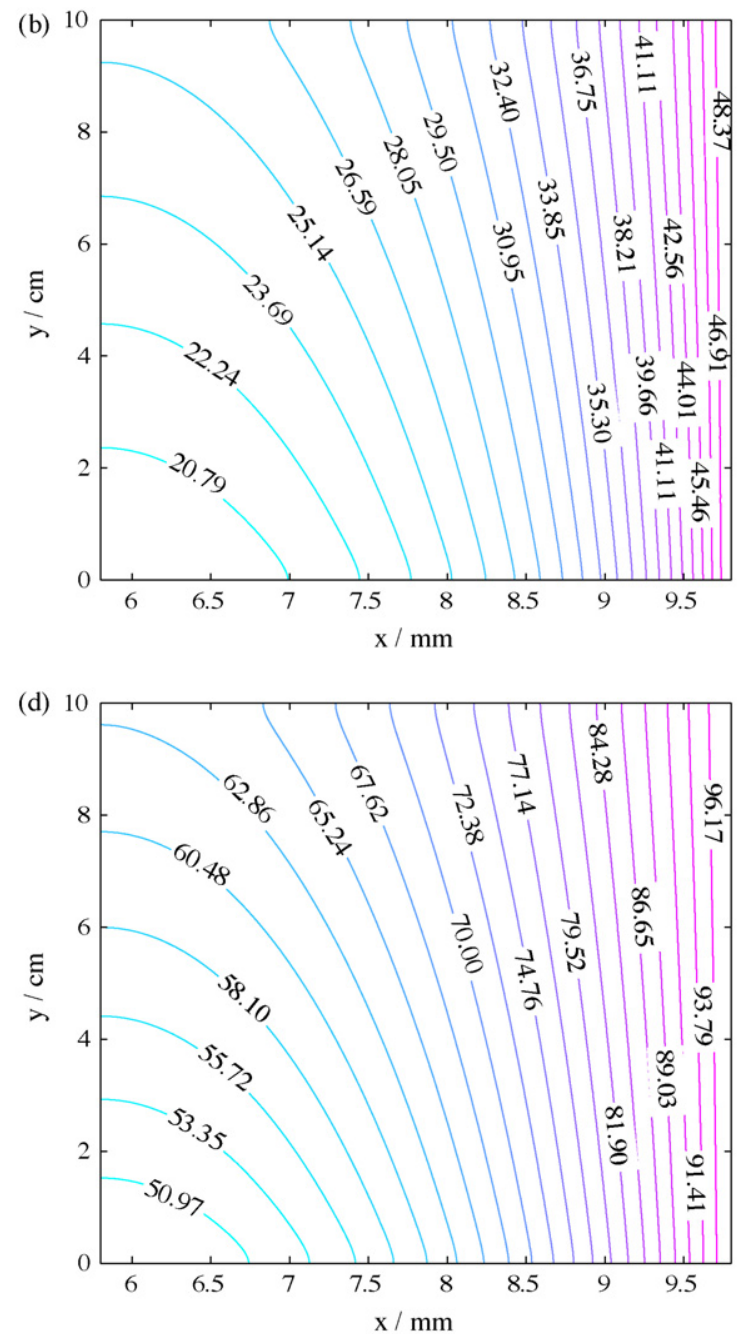

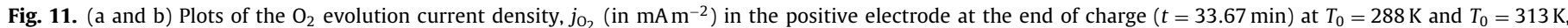

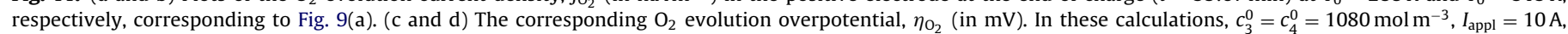
$d_{g}=50 \mu \mathrm{m}, Q=1 \mathrm{~mL} \mathrm{~s}^{-1}$ and $T_{0}=298 \mathrm{~K}$. The other parameter values are given in Tables 2, 4-7. 

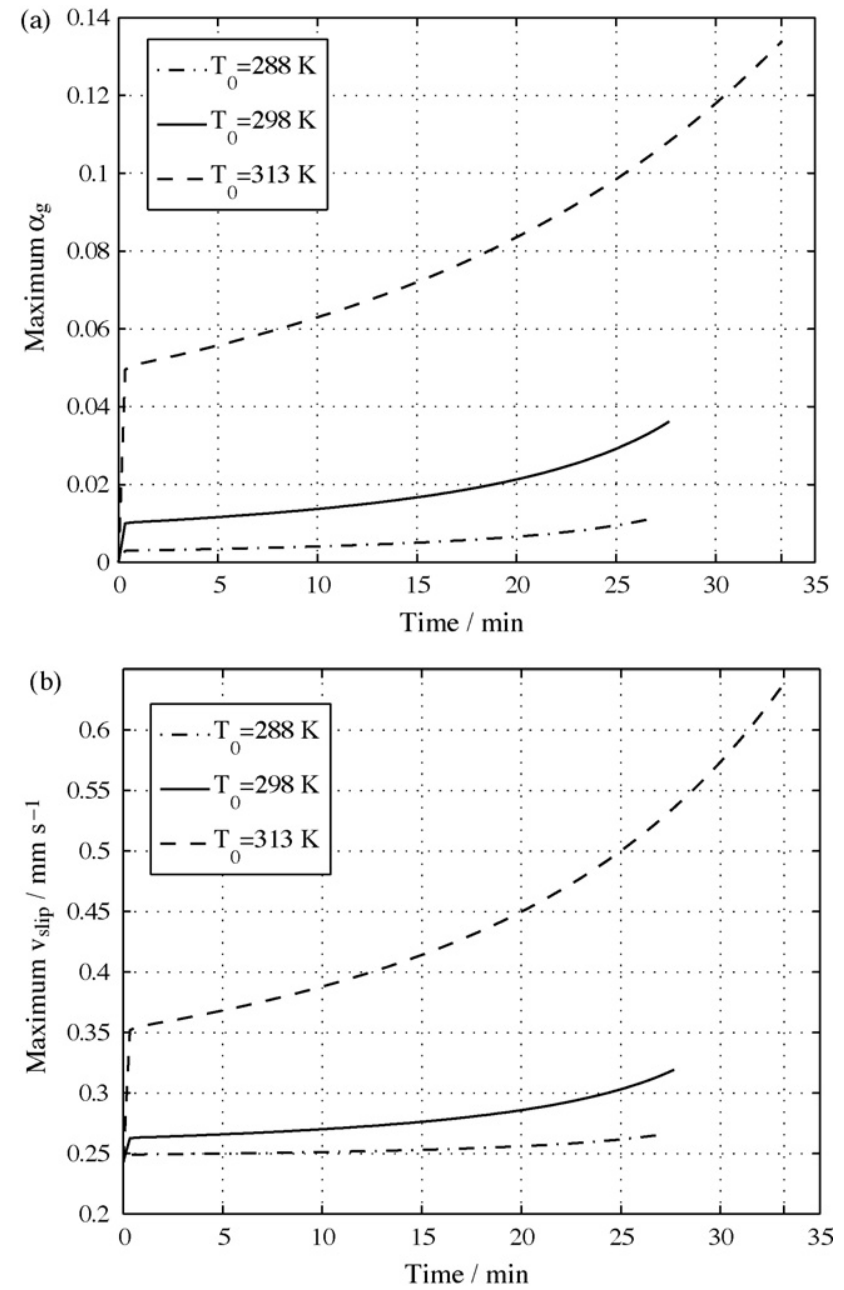

Fig. 12. Plots of the maximum value of: (a) the gas volume fraction, $\alpha_{g}$; (b) the $y$ component of the slip velocity, $v_{\text {slip }}$ (in $\mathrm{mm} \mathrm{s}^{-1}$ ) in the positive electrode during the charge cycles (to $S O C=0.73$ ) at different temperatures in Fig. 9 (b). In these calculations, $c_{3}^{0}=c_{4}^{0}=1080 \mathrm{~mol} \mathrm{~m}^{-3}, I_{\mathrm{appl}}=10 \mathrm{~A}, d_{g}=50 \mu \mathrm{m}$ and $Q=1 \mathrm{~mL} \mathrm{~s}^{-1}$. The other parameter values are given in Tables $2,4-7$

of the $\mathrm{O}_{2}$ evolution current density increases by more than $350 \%$, on the order of the increase in the gas volume fraction. In contrast, Fig. 11(c) and (d) shows that $\mathrm{O}_{2}$ evolution overpotential in the positive electrode, $\eta_{\mathrm{O}_{2}}$ at the end of the charge decreases by as much as $148 \mathrm{mV}$ as the temperature is increased from $T_{0}=288-313 \mathrm{~K}$. The rate constant for the $\mathrm{O}_{2}$ evolution reaction, given in Eq. (23) depends exponentially on temperature. The increase in the overpotential value at the lower temperature is outweighed by the decrease in the reaction rate constant, which leads to much lower values of $j_{\mathrm{O}_{2}}$.

Fig. 9(b) shows the cell potential difference curves at three temperatures when the charge phase is terminated at an equivalent state of charge $(S O C=0.73)$ in all cases. As the temperature is raised, the $\mathrm{O}_{2}$ evolution reaction consumes a greater portion of the applied current density, leading to increasingly longer (charge) times to the same SOC: $27.07,27.93$ and $33.67 \mathrm{~min}$, in order of ascending temperature. The trend in these values reflects the exponential increase in the rate constant for the $\mathrm{O}_{2}$ reaction with temperature, as does the plot of the maximum gas volume fraction shown in Fig. 12(a). The slip velocity increases as a consequence, which will partially offset the increase in $\alpha_{g}$ (Fig. 12(b)). Also evident from Fig. 9(b) is that the charge efficiencies at the different temperatures are roughly similar since the capacity of the battery at the end of charge is theoretically the same in each case.

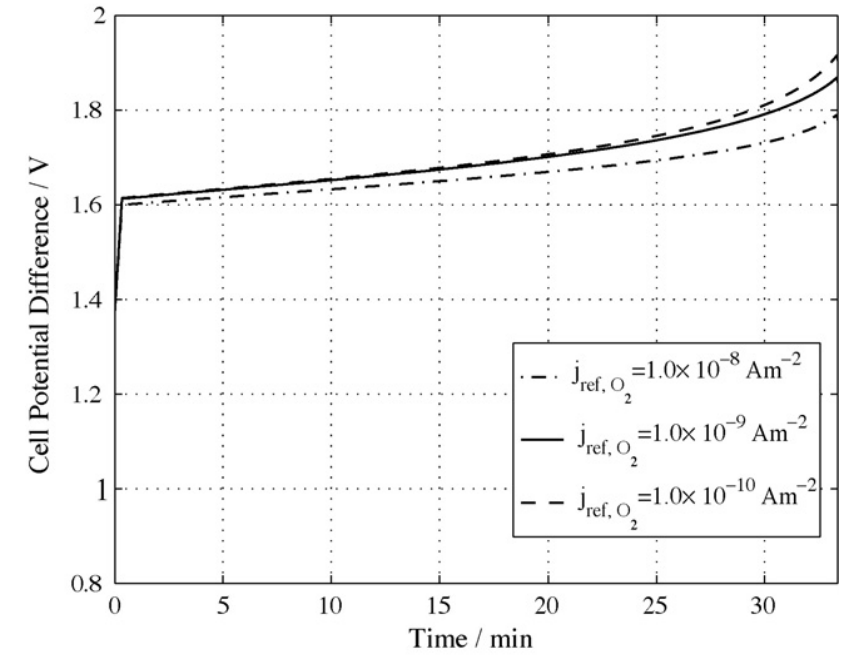

Fig. 13. The cell potential difference curves during charge for different values of $j_{\text {ref, } \mathrm{O}_{2}}$. In these calculations, $c_{3}^{0}=c_{4}^{0}=1080 \mathrm{~mol} \mathrm{~m}^{-3}, I_{\text {appl }}=10 \mathrm{~A}, Q=1 \mathrm{~mL} \mathrm{~s}^{-1}, d_{g}=$ $50 \mu \mathrm{m}$ and $T_{0}=298 \mathrm{~K}$. The other parameter values are given in Tables 2, 4-7
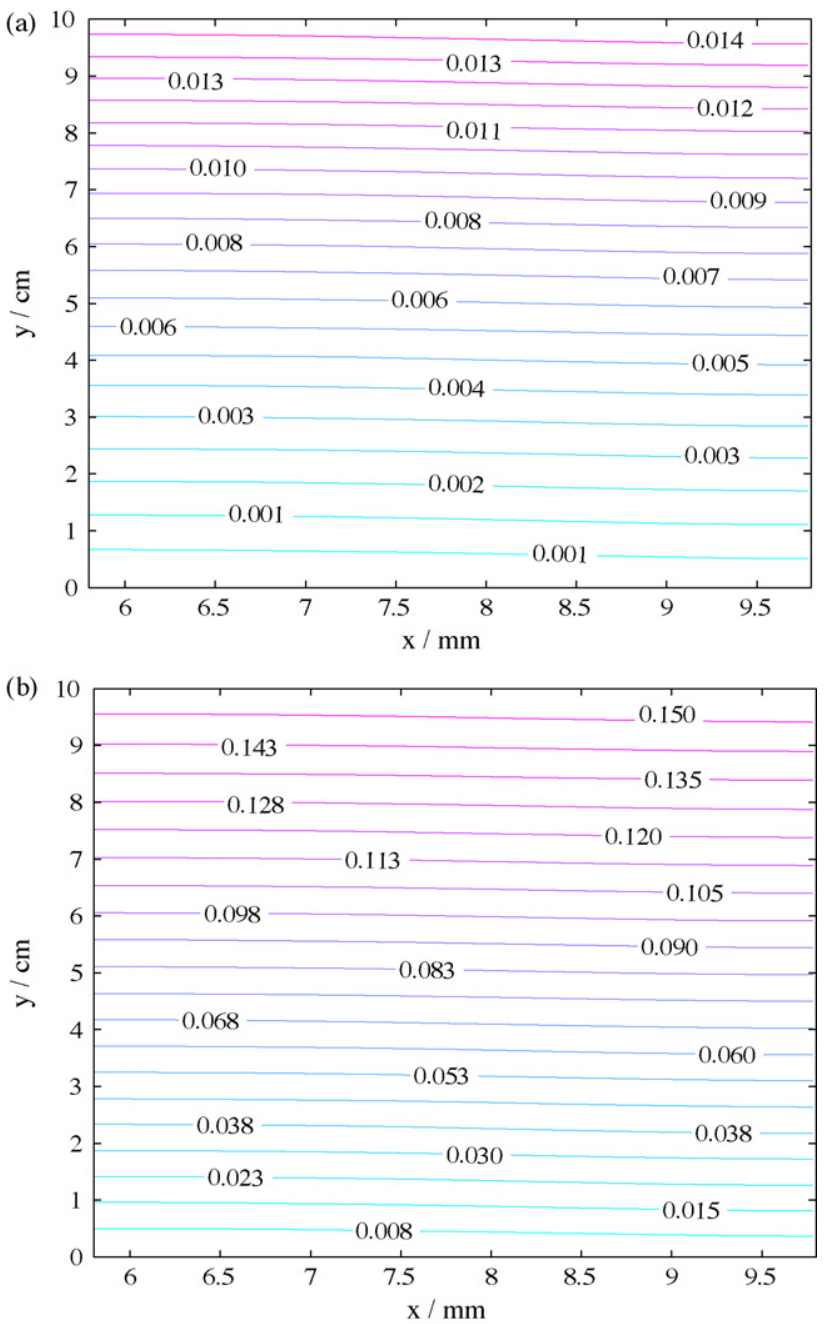

Fig. 14. The $\mathrm{O}_{2}$ volume fraction for (a) $j_{\mathrm{ref}, \mathrm{O}_{2}}=1 \times 10^{-10} \mathrm{Am}^{-2}$ and (b) $1 \times$ $10^{-8} \mathrm{~A} \mathrm{~m}^{-2}$. In these calculations, $c_{3}^{0}=c_{4}^{0}=1080 \mathrm{~mol} \mathrm{~m}^{-3}, I_{\text {appl }}=10 \mathrm{~A}, Q=1 \mathrm{~mL} \mathrm{~s}^{-1}$, $d_{g}=50 \mu \mathrm{m}$ and $T_{0}=298 \mathrm{~K}$. The other parameter values are given in Tables $2,4-7$. 


\subsection{Oxygen evolution parameters}

The electrochemical parameters for $\mathrm{O}_{2}$ evolution will clearly depend on the electrode material. To provide an indication of the differences between $\mathrm{O}_{2}$ evolution on different materials, and to confirm that the behaviour described above is robust to changes in the parameter values, calculations were performed with different $j_{\text {ref, } O_{2}}$ values (all other parameters unchanged). Fig. 13 shows the cell potential difference curves during charge for all cases. The $\mathrm{O}_{2}$ volume fractions at the end of charge for $j_{\text {ref, } \mathrm{O}_{2}}=1 \times 10^{-10}$ and $1 \times 10^{-8} \mathrm{~A} \mathrm{~m}^{-2}$ are plotted in Fig. 14. These figures show that, as expected, an increased value of $j_{\mathrm{ref}, \mathrm{O}_{2}}$ leads to a greater decrease in the cell potential difference, as a consequence of a increased current consumed by the parasitic $\mathrm{O}_{2}$ evolution reaction and a greater volume of $\mathrm{O}_{2}$. The results discussed in previous sections, however, are qualitatively unchanged.

\section{Conclusions}

A non-isothermal two-dimensional dynamic model of an allvanadium redox flow battery based on mass, charge, energy and momentum transport and conservation, together with a kinetic model for redox and gas-evolving reactions has been developed. The impact of $\mathrm{O}_{2}$ evolution and gas bubble formation in the positive electrode during charge on the performance was investigated. Evolved oxygen, in the form of bubbles, impacts performance by reducing the active surface area for electrochemical reaction in the electrode, reducing the effective diffusion coefficients, lowering the effective ionic and thermal conductivities and by altering the flow field. Comparison between numerical simulations and experimental data, for different vanadium concentrations and electrolyte flow rates, demonstrate good qualitative and quantitative agreement. The maximum in the oxygen volume was shown to range from $2 \%$ to approximately $13 \%$ of the total volume over a typical charge-discharge cycle, for the parameter values used. The effect of oxygen evolution is a drop in charge efficiency on the order of $5-10 \%$.

The $\mathrm{O}_{2}$ evolution reaction consumes a portion of the (fixed) applied current, reducing the amount of current available for the oxidation of $\mathrm{V}(\mathrm{IV})$. The time to an equivalent state of charge is, therefore, increased and the capacity of the cell for a fixed-charge time is reduced. Increasing the mean linear electrolyte flow rate was found to reduce the volume of the oxygen gas in the positive electrode. This is due mainly to the increased rate at which the gas is removed from the cell since the flow is convection dominated. The lower overpotentials achieved with a higher flow rate further reduce the gas volume fraction.

The oxygen gas volume fraction and velocity are strongly influenced by the bubble diameter. The slip velocity increases with bubble diameter as a result of a greater buoyancy force exerted on the bubbles. The gas volume fraction decreases as the gas is removed at a faster rate. Substantial changes are observed over the range of reported bubble diameters.

Increasing the operating temperature was found to enhance $\mathrm{O}_{2}$ evolution and, therefore, increase the volume of gas in the positive electrode. The exponential dependence of the reaction rate constant for $\mathrm{O}_{2}$ evolution outweighs several competing factors, including increases in the slip velocity and the magnitudes of the overpotentials, to increase the gas volume fraction at higher temperatures. Since the rate of evolution is enhanced at higher temperature, and the onset occurs sooner in the charge cycle, at fixed values of the other parameters, the rate of oxidation in the positive electrode decreases at any fixed time. Thus, the time required to reach an equivalent state of charge (charge time) increases with temperature. The charge efficiency of the cell drops markedly as a consequence. The drop in efficiency is nonlinear since the main factor associated with the drop (the $\mathrm{O}_{2}$ reaction constant) has an exponential dependence on temperature.

\section{References}

[1] C. Ponce de Léon, A. Frías-Ferrer, J. González-Garcia, D.A. Szánto, F.C. Walsh, J. Power Sources 160 (2006) 716.

[2] A. Pellegri, P.M. Spaziante, UK Patent GB 2030349 A (July 1978).

[3] M. Skyllas-Kazacos, C. Menictas, Proceedings, Intelec, Melbourne, 1997.

[4] M. Skyllas-Kazacos, R.G. Robins, US Patent 849094 (1986).

[5] E. Sum, M. Skyllas-Kazacos, J. Power Sources 15 (1985) 179

[6] P. Boissonneau, P. Byrne, J. Appl. Electrochem. 30 (2000) 767.

[7] M.Y. Christi, Airlift Bioreactors, Elsevier Science Publications, 1989.

[8] F. Hine, K. Murakami, J. Electrochem. Soc. 127 (1980) 292.

[9] M.D. Mat, K. Aldas, Int. J. Hydrogen Energy 30 (2005) 411.

[10] A.A. Shah, H. Al-Fetlawi, F.C. Walsh, Electrochim. Acta 55 (2010) 1125

[11] M. Manninen, V. Taivassalo, S. Kallio, On the Mixture Model for Multiphase Flow, Technical Report VTT Publications 288, Technical Research Centre of Finland, 1996.

[12] H. Al-Fetlawi, A.A. Shah, F.C. Walsh, Electrochim. Acta (2009).

[13] A.A. Shah, M.J. Watt-Smith, F.C. Walsh, Electrochim. Acta 53 (2008) 8087.

[14] Ch. Fabjan, J. Garche, B. Harrer, L. Jőrissen, C. Kolbeck, F. Philippi, G. Tomazic, F. Wagner, Electrochim. Acta 47 (2001) 825

[15] M. Gattrell, J. Park, B. MacDougall, J. Apte, S. McCarthy, C.W. Wu, J. Electrochem. Soc. 151 (2004) 123.

[16] M.M. Saleh, J. Solid State Electrochem. 11 (2007) 811.

[17] J. Newman, Electrochemical Systems, Prentice Hall, Engelwood Cliffs, NJ, 1991.

[18] A.A. Dahlkild, J. Fluid Mech. 428 (2001) 249.

[19] H. Vogt, Electrochim. Acta 25 (1980) 527.

[20] H. Vogt, J. Electrochem. Soc. 137 (1990) 1179

[21] L.J.J. Janssen, Electrochim. Acta 23 (1978) 81.

[22] G. Marrucci, L. Nicodemo, Chem. Eng. Sci. 22 (1967) 1257.

[23] D.A. Drew, Ann. Rev. Fluid Mech. 15 (1980) 261.

[24] G. Ahmadi, D. Ma, Int. J. Multiphase Flow 16 (1990) 323.

[25] R.A. Freeze, J.A. Cherry, Groundwater, Prentice-Hall, New Jersey, 1979.

[26] B. Bird, W. Stewart, E. Lightfoot, Transport Phenomena, John Wiley and Sons, NY, 2002.

[27] S. Motupally, A.J. Becker, J.W. Weidner, J. Electrochem. Soc. 147 (2000) 3171.

[28] I. Rubenstein, Physical Electrochemistry, Marcel Dekker, 1995.

[29] S.G. Bratsch, J. Phys. Chem. Ref. Data 18 (1989) 1.

[30] J. González-Garciá, P. Bonete, E. Expósito, V. Montiel, A. Aldaz, R. TorregrosaMaciá, J. Mater. Chem. 9 (1999) 419.

[31] R. Carta, S. Palmas, A.M. Polcaro, G. Tola, J. Appl. Electrochem. 21 (1991) 793.

[32] N. Vatistas, P.F. Marconi, M. Bartolozzi, Electrochim. Acta 36 (1991) 339

[33] L.J.J. Janssen, J.G. Hoogland, Electrochim. Acta 15 (1970) 1013.

[34] D. Ziegler, J.W. Evans, J. Electrochem. Soc. 103 (1986) 567.

[35] M.M. Saleh, M.H. El-Ankily, M.S. El-Deab, B.E. El-Anadouli, Bull. Chem. Soc. Jpn. 79 (2006) 1711.

[36] M. Pourbaix, Atlas of Electrochemical Equilibria in Aqueous Solutions, second ed., NACE International, Houston, 1974.

[37] D.M. Bernadi, M.W. Verbrugge, AIChE J. 37 (1991) 1151.

[38] C. Ziegler, A. Schmitz, M. Tranitz, E. Fontes, J.O. Schumacher, J. Electrochem. Soc. 151 (2004) 2028.

[39] A. Bard, R. Parsons, J. Jordan, Standard Potentials in Aqueous Solution, Marcel Dekker, New York, 1985.

[40] T. Yamamura, M. Watanabe, T. Yano, Y. Shiokawa, J. Electrochem. Soc. 152 (2005) A830.

[41] R. Mills, Phys. Chem. 77 (1973) 685.

[42] T.E. Springer, T.A. Zawodinski, S. Gottesfeld, J. Electrochem. Soc. 138 (1991) 2334.

[43] M.W. Verbrugge, R.F. Hill, J. Electrochem. Soc. 137 (1990) 886.

[44] J.C. Brown, Tappi J. 33 (1950) 130.

[45] J.L. Fales, N.E. Vandeborough, Electrochem. Soc. Proc. 86 (1986) 179 